\title{
LA FRACTURACIÓN DE HUESOS LARGOS DURANTE EL HOLOCENO MEDIO EN EL MACIZO DEL DESEADO. IMPLICANCIAS PARA EL ESTUDIO DEL APROVECHAMIENTO DE LOS GUANACOS
}

\author{
THE LONG BONES FRACTURE DURING MIDDLE HOLOCENE IN THE \\ DESEADO MASSIF. IMPLICATIONS TO THE STUDY OF GUANACO USE
}

\author{
Laura Marchionni ${ }^{1}$, Eloisa García Añino², Laura Miotti ${ }^{3}$ \\ ${ }^{1}$ CONICET/División Arqueología, Facultad de Ciencias Naturales y Museo-UNLP; \\ E-mail: lau_marchionni@yahoo.com.ar \\ ${ }^{2}$ División Arqueología, Facultad de Ciencias Naturales y Museo-UNLP; \\ E-mail: eloisagarcia89@yahoo.com.ar \\ ${ }^{3}$ CONICET/División Arqueología, Facultad de Ciencias Naturales y Museo-UNLP; \\ E-mail: laura.miotti2@gmail.com
}

Presentado: 17/04/2019 - Aceptado: 11/10/2019

\section{Resumen}

En el presente trabajo evaluamos la variabilidad existente en la fracturación de los huesos largos de Lama guanicoe (guanaco) durante el Holoceno medio en la Meseta Central de Santa Cruz (Patagonia argentina). Para ello analizamos los conjuntos zooarqueológicos de la capa 2 de AEP-1 de Piedra Museo y del componente 2 de Cueva Maripe en La Primavera. Ambos contextos se emplazan en sectores diferentes de la cuenca de los zanjones Rojo y Blanco y en trabajos previos fueron definidos como espacios domésticos con diversas áreas de actividades (Cattáneo 2002; García Añino 2018; Lynch 2014; Marchionni 2013). Éste trabajo tiene como objetivo alcanzar una mejor comprensión de las estrategias de uso y aprovechamiento de los guanacos por parte de los cazadores-recolectores que habitaron esta región y aportar información de grano fino para el estudio de la variabilidad registrada en los sitios que solemos definir como domésticos o de actividades múltiples. El estudio se centra en el análisis de las distintas actividades que pudieron involucrar la fracturación intencional de los huesos. Los resultados muestran diferencias entre los conjuntos, siendo mayor la variabilidad de actividades que se expresan en los conjuntos de Cueva Maripe.

Palabras claves: consumo, tecnología ósea, ungulados, cazadores-recolectores, Patagonia.

\begin{abstract}
In the present work we evaluate the existing variability in the fracture patterns of the long bones of the Lama guanicoe (guanaco) during the Middle Holocene in the Central Plateau of Santa Cruz (Argentine Patagonia). To do this, we analyzed the zooarchaeological assemblages of layer 2 of AEP-1 of Piedra Museo and of component 2 of Cueva Maripe. Both contexts are located in different sector of the Zanjones Rojo and Blanco basin, which in previous works have been defined as domestic sites with different activity areas (Cattáneo 2002; García Añino 2018; Lynch 2014; Marchionni 2013). The work goals is to reach a better understanding of the use
\end{abstract}


and exploitation strategies of the guanacos by hunter-gatherers that inhabit this region and provide fine-grained information for the study of the registered variability in the sites that we usually define as of multiple activities. The study focuses on the analysis of the different activities that involve the intentional fracture the bones. The results show differences among assemblages, which are expressed as a greater variety of activities in Cueva Maripe.

Key words: consumption, bone technology, ungulate, hunter-gatherer, Patagonia.

\section{Introducción}

Las sociedades cazadoras recolectoras que habitaron el sector extra-andino de Patagonia meridional basaron su subsistencia, desde los inicios del poblamiento de la región, en la explotación del guanaco (Lama guanicoe). Estos ungulados ya se encontraban disponibles en el área cuando los primeros humanos arribaron a ella ca. 12000 años AP, y la evidencia arqueológica indica su aprovechamiento como recurso principal a lo largo de toda la ocupación humana del área, incluso hasta momentos tardíos del Holoceno (Aguerre 1994; Aguerre et al. 1994 a y b; De Nigris 2004, 2008; Durán et al. 2003; Frank 2011; Horovitz 1994; Marchionni 2013; Marchionni et al. 2010; Miotti 1998; Miotti et al. 1999, 2005; Mengoni y Silveira 1976; Mengoni Goñalons 1999; Paunero et al. 2007; Rindel 2009, entre otros muchos). Sin embargo, la forma e intensidad en la que los guanacos fueron procesados por estos grupos han variado a lo largo del tiempo y el espacio en la región, incluso en escala intrasitio vemos que puede monitorearse esta variabilidad, siendo en estos casos posiblemente debida a la estructuración humana del espacio habitacional. La bibliografía existente sobre este tema destaca que hacia el Holoceno medio en Patagonia se registra un cambio desde una economía generalizada durante la transición Pleistoceno-Holoceno y el Holoceno temprano, caracterizada por el aprovechamiento, además del guanaco, de distintas especies de mamíferos pleistocénicos y aves, hacia una estrategia especializada en la captura y explotación de los guanacos durante el Holoceno medio, donde las aves habrían sido un recurso complementario (Miotti y Salemme 1999, 2004; Miotti et al. 2018; Salemme y Miotti 2008). Cambios similares a los registrados en Patagonia fueron sugeridos para la región pampeana, donde para el Holoceno medio también fue propuesta una estrategia económica regional, especializada en el aprovechamiento del guanaco, y que difiere de la estrategia generalizada que tuvo lugar en momentos previos (Martínez y Gutiérrez 2004; Martínez et al. 2016).

El Holoceno medio en Patagonia (entre $c a \cdot 7,5$ y 3 ka AP), corresponde a un período en el que, al igual que en otras regiones del país, se producen diversos cambios ambientales y ecológicos, tanto a escala global como regional (Zárate et al. 2005), y que en algunos sectores, han resultado en una reestructuración de los recursos y producido cambios tanto en los patrones de asentamiento de las sociedades cazadorasrecolectoras, como en las estrategias económicas (Barberena 2008; Cortegoso et al. 2014; Martínez et al. 2015; Miotti 2012; Neme y Gil 2008, 2009; Núñez et al. 2011; Yacobaccio et al. 2011; Zangrando et al. 2010, entre otros). En la región patagónica, este período se 
caracteriza por aumentos del nivel del mar (Rabassa 1987, 2008; Rabassa et al. 1989), de la temperatura y la humedad (hipsitermal), los cuales, en la región extra andina, con alternancia de pulsos húmedos y áridos, no produjeron cambios significativos en la estructura faunística (Miotti 1998). El trabajo realizado por Mosquera (2018) a partir de 130 fechados radiocarbónicos procedentes de 28 sitios arqueológicos ubicados en el Macizo del Deseado, permite reconocer discontinuidades cronológicas para el área. Particularmente en lo referido al Holoceno medio identifica un hiato cronológico entre 7828 y 6434 años cal. AP (Mosquera 2018). Si bien este hiato podría responder a sesgos de muestreo o tafonómicos, es probable que esté dando cuenta de cambios en la dinámica de movilidad de los grupos, ya que, el incremento de la aridez regional habría afectado la productividad de las fuentes de agua y, en consecuencia, el uso del Macizo podría haber mermado (Mosquera 2016, 2018 y bibliografía allí citada). En cuanto a las comunidades vegetales no se registran grandes cambios, el común denominador es un aumento progresivo de la temperatura (De Porras 2010) y el cambio de una estepa graminosa a una arbustiva (Borromei 2003; De Porras 2010; Mancini 1998).

El registro arqueofaunístico del área se encuentra dominado por la presencia de $L$. guanicoe y no se registra la fauna pleistocénica que se reconoce en el período anterior. Respecto de este punto, para el Holoceno medio los índices de abundancia indican menor diversidad taxonómica que para el Pleistoceno final- Holoceno temprano (Martínez et al. 2016; Miotti y Salemme 1999). En cuanto a la representación anatómica, se destaca la predominancia de elementos apendiculares de los guanacos, los cuales suelen estar muy fragmentados (De Nigris 2008; García Añino 2018; Marchionni 2013; Miotti y Marchionni 2011; Rindel 2009).

Sobre esta base, en el presente trabajo buscamos explorar las causas de la variabilidad de la fracturación en el NE del Macizo del Deseado durante el Holoceno medio. Partimos de la idea de que las distintas decisiones tomadas en el procesamiento de estas presas se reflejan en los patrones de fragmentación observados en el registro arqueológico y por lo tanto, el estudio de detalle de esa fragmentación conforma una herramienta metodológica válida para avanzar sobre la variabilidad de prácticas y estrategias que dan cuenta de los diversos intereses humanos que orientaron el procesamiento de las presas. Esperamos brindar un panorama ampliado del aprovechamiento de los recursos faunísticos, particularmente en lo que refiere a la explotación diferencial del esqueleto apendicular de los guanacos, la cual, hasta ahora, ha quedado homogeneizada en la caracterización de las actividades principales que tuvieron lugar en sitios interpretados como de "actividades domésticas".

El estudio de la fragmentación ósea permite abordar tanto, aspectos vinculados a la preservación de los conjuntos, como otros relacionados con las diversas estrategias de procesamiento y consumo de los recursos faunísticos, sean estos alimenticios o no (Bourlot 2009; De Nigris 2004, 2008; Miotti 1998; Mengoni Goñalons 1999; Mengoni y De Nigris 1999; Rindel 2013; entre muchos otros). Si bien determinados patrones de 
fracturas podrían indicar el consumo de médula ósea (Bourlot et al. 2008; García Añino 2018; Mengoni Goñalons y De Nigris 1999; Muñoz y Belardi 1998), también podrían dar cuenta de la búsqueda de formas base para la manufactura de artefactos óseos (Belardi et al. 2010; Hajduck y Lezcano 2005; Miotti 1998; Miotti y Marchionni 2013; Muñoz y Belardi 1998; Santiago y Salemme 2016). En este sentido, la presencia de determinadas modificaciones asociadas a los bordes de fractura sugiere la preparación previa del hueso para guiar la fuerza del golpe y lograr una fractura controlada (Lyman 1994; Mengoni Goñalons 1999; Miotti 1992). Así, a partir de este trabajo discutimos las formas de prácticas de aprovechamiento vinculadas a la fracturación de los huesos largos y cómo ellas pueden estar dando cuenta de diversas actividades en sitios residenciales o domésticos.

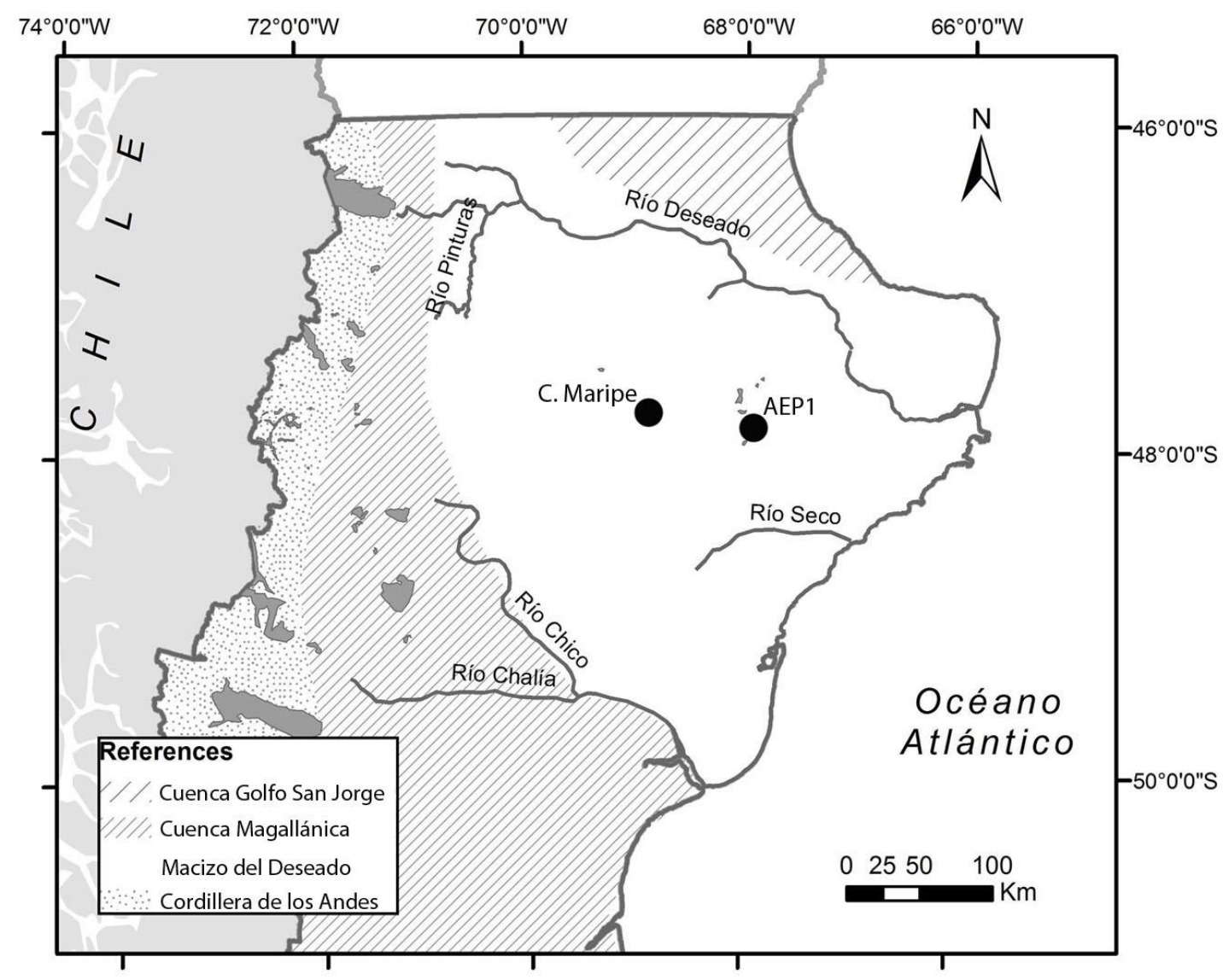

Figura 1. Área de estudio y localización de los sitios investigados

Para llevar adelante este estudio seleccionamos los conjuntos arqueofaunísticos del Holoceno Medio de los sitios Alero El Puesto 1 (AEP-1) de Piedra Museo y Cueva Maripe (CM) del Cañadón La Primavera. AEP-1 se localiza en el sector de base de la cuenca de los zanjones Rojo y Blanco (NE del Macizo del Deseado), mientras que CM se emplaza en el sector de cabecera, distantes entre sí aproximadamente unos $80 \mathrm{~km}$ (Figura 1). La selección de estos dos contextos se debe a que los análisis zooarqueológicos y tafonómicos realizados hasta el momento muestran la existencia de tendencias similares respecto de la explotación de los guanacos (Marchionni 2012, 2013; 
2016; Miotti y Marchionni 2011). Dichas similitudes derivan de la representación semejante, no solo de las unidades anatómicas de los guanacos, sino también de la frecuencia y variedad de marcas de procesamiento, que, en ambos sitios, dan cuenta de las diferentes etapas del procesamiento de estos ungulados (García Añino 2018; García Añino et al. 2014; Marchionni 2013). Esta información, sumada a la presencia de fogones y la distribución de restos óseos en torno a ellos (Lynch et al. 2016; Marchionni 2013, 2016; Miotti y Marchionni 2011), así como la proveniente de otras líneas de investigación (Carden 2009; Cattáneo 2002; Hermo 2008; Lynch 2014), conforman la base sobre la que estos conjuntos fueron definidos como resultado de actividades domésticas de grupos cazadores-recolectores (Miotti y Marchionni 2011; Miotti et al. 2014). Es posible que, al menos en parte, los intereses que los grupos humanos tuvieron para asentarse en un sector $u$ otro de la cuenca y procesar de manera particular sus presas, hayan estado vinculados a las diferencias ambientales que existen entre ambas localidades (Marchionni 2013). Si bien la disponibilidad de recursos es similar, con posibilidad de uso estacional de ambos puntos, las diferentes altitudes que existen entre ambos (CM se emplaza a $540 \mathrm{msnm}$ y AEP-1 lo hace a $140 \mathrm{msnm}$ ), llevan durante el invierno a la existencia de una mayor rigurosidad climática en cañadón La Primavera. Además de las diferencias ambientales entre AEP-1 CM, existen diferentes factores sociales, demográficos, simbólicos, que deben haber jugado un rol destacado en la forma de procesar y aprovechar los guanacos (i.e. circuitos de movilidad, fisión y fusión social, tecnologías, preferencias y formas de compartir los alimentos, entre otros). Por ello, el estudio de mayor detalle de la fragmentación ósea que aquí proponemos llevar a cabo, constituye un enfoque apropiado para rastrear el aprovechamiento de guanacos a nivel intra e inter sitio, tanto en la forma de fracturar los huesos, como en los motivos que condujeron a la misma y, a partir de ello, contribuir al estudio de la variabilidad existente entre sitios cuya funcionalidad habría sido la misma, en este caso, espacios domésticos.

Trabajos previos realizados en Patagonia meridional han explorado la fragmentación existente en los conjuntos zooarqueológicos para momentos del Holoceno tardío principalmente, contemplando el rol que jugó la obtención de grasa medular y ósea en dicha fragmentación (Bourlot 2009; Mengoni Goñalons y De Nigris 1999; Rindel 2009, 2013). Todos estos trabajos destacan la importancia que habría tenido la explotación de ambos tipos de grasa, como recurso estable y predecible en momentos de estrés nutricional, no solo para su consumo inmediato sino también para uso diferido. Asimismo, las investigaciones desarrolladas por Rindel (2013) hacen referencia a una selección de unidades anatómicas por parte de los cazadoresrecolectores en función de la calidad de la grasa medular presente en los distintos huesos largos de guanaco. A diferencia de esos estudios previos, el presente trabajo pone en pie de igualdad los múltiples intereses que pueden estar detrás de este tipo de procesamiento -consumo alimenticio, manufactura de herramientas-, aportando información novedosa acerca de las distintas formas de utilización de los guanacos durante el Holoceno medio en Patagonia. 


\section{Caracterización de los conjuntos estudiados}

Estudiamos tres conjuntos zooarqueológicos que provienen, tal como fue mencionado anteriormente, de los sitios AEP- 1 y CM, cada uno de estos sitios se emplaza en un sector distinto dentro de la cuenca de los zanjones Rojo y Blanco (Santa Cruz, Argentina- ver figura 1). Si bien ambos contextos presentan secuencias ocupacionales que se remontan a los inicios del poblamiento del área, durante la transición Pleistoceno- Holoceno, para este trabajo nos enfocamos en los conjuntos con fechados correspondientes al Holoceno medio. En este sentido, los conjuntos aquí analizados son: Capa 4 de Cámara Norte $(\mathrm{CN})$ de $\mathrm{CM}$, con fechados entre ca. 5300 y $3200{ }^{14} \mathrm{C}$ AP; Unidad Analítica (UA) 2 de Cámara Sur (CS) de CM, con dataciones de entre ca. 7700 y $4100{ }^{14} \mathrm{C}$ AP, ambos en la localidad arqueológica La Primavera (Miotti et al. 2014); y por último, el conjunto de Capa 2 de AEP-1 (Piedra Museo), con cronologías de entre ca. 7700 y 7400 años ${ }^{14} \mathrm{C}$ AP (Miotti et al. 2003). Las frecuencias de $\%$ NISP en los tres conjuntos indican que el guanaco es la especie más representada durante el Holoceno medio en la cuenca, con claras evidencias de procesamiento (Tabla 1). La menor representación relativa de los guanacos en AEP-1 respecto de CM se debe, principalmente, a una mayor frecuencia de especímenes pequeños sin rasgos diagnósticos que no pudieron ser asignados a niveles taxonómicos más específicos que el de mamífero indeterminado o mamífero grande. No obstante, otras especies como los rheidos, los cánidos, las aves y los moluscos, también se han registrado en conjuntos del Holoceno medio de la cuenca y presentan claras evidencias de utilización humana (Tabla 1).

\begin{tabular}{|l|c|c|c|c|c|c|}
\cline { 2 - 7 } \multicolumn{1}{c|}{} & \multicolumn{2}{c|}{ Capa 2-AEP-1 } & \multicolumn{2}{c|}{ Capa 4 CM } & \multicolumn{2}{c|}{ Unidad Analítica 2 CM } \\
\cline { 2 - 8 } & NISP & $\%$ NISP & NISP & $\%$ NISP & NISP & \% NISP \\
\hline Mollusca & 4 & 0,22 & & & & \\
\hline Ave indet. & 67 & 3,66 & 1 & 0,13 & & \\
\hline Rheidae* & 123 & 6,71 & 132 & 16,65 & 2 & 0,49 \\
\hline Mamífero Indet. & 997 & 54,39 & 114 & 14,38 & 48 & 11,74 \\
\hline Mamífero Grande & 146 & 7,97 & 196 & 24,72 & 132 & 32,27 \\
\hline Dasipodidae sp. & 3 & 0,16 & 2 & 0,25 & & \\
\hline Rodentia indet. & & & 3 & 0,38 & & \\
\hline Carnivora & 6 & 0,33 & 6 & 0,76 & & \\
\hline Artiodactyla & & & 6 & 0,76 & & \\
\hline Camelidae & & & 4 & 0,50 & & \\
\hline Lama sp. & & & 1 & 0,13 & & \\
\hline Lama guanicoe & 487 & 26,57 & 328 & 41,36 & 227 & 55,50 \\
\hline Subtotal & 1833 & & 793 & & 409 & \\
\hline Indeterminado & 566 & & 1836 & & 962 & \\
\hline Total & 2399 & & 2629 & & 1371 & \\
\hline *incluye cáscaras de huevo & & & & & \\
\hline
\end{tabular}

Tabla 1. Abundancia taxonómica en los conjuntos del Holoceno medio 
En base a las frecuencias de \%MAU obtenidas para el guanaco, podemos observar que para el Holoceno medio del Macizo, los conjuntos zooarqueológicos se encuentran principalmente representados por elementos apendiculares, entre ellos se observa una preponderancia de las porciones más distales de los miembros (Tabla 2). Por otro lado, el hecho de que en ambos conjuntos de CM, el sacro registre frecuencias elevadas, nos permite pensar que la cintura pélvica habría ingresado al sitio acompañando a los cuartos traseros, lo que podría estar indicando diferentes formas de trozamientotransporte-distribución y/o reparto, entre los distintos sectores de la cuenca.

Los estudios tafonómicos realizados mostraron que estos conjuntos presentan un buen estado de preservación, siendo el conjunto de la UA2 de CM el que se encuentra menos meteorizado (no se registran especímenes en estadios superiores a 2), mientras que los conjuntos de Capa 4 de CM y de Capa 2 de AEP-1 exhiben $c a$. del $96 \%$ y $94 \%$ de los especímenes en estadio igual o menor a 2, respectivamente, presentando porcentajes mínimos en estadio 3, por lo que es probable la pérdida de información ósea (para mayor detalle ver Marchionni 2013, 2016). Entre los principales agentes naturales que intervinieron en la formación de estos conjuntos, para los casos de CM los valores más abultados se registran en los depósitos de manganeso, los cuales en $\mathrm{CN}$ están presentes en $c a .6 \%$ de los especímenes y en CS en $c a$. $10 \%$, mientras que modificaciones producidas por raíces, roedores, carbonatos o carnívoros fueron observadas en $<3 \%$ de los especímenes (Marchionni 2013, 2016; Miotti et al. 2014). En cuanto al conjunto de AEP-1, los principales procesos de formación están vinculados al desarrollo del paleosuelo, destacándose modificaciones por raíces (ca. 26\% del NISP), depósitos de manganeso (ca. 19\% del NISP) y carbonatos (ca. 6\% del NISP), mientras otras modificaciones, como las producidas por carnívoros (ca. 2,5\% del NISP), no parecen relevantes en la formación del conjunto (Marchionni 2013, 2016; Miotti y Marchionni 2011). De esto se desprende que las modificaciones observadas corresponden a procesos y agentes que no parecen haber puesto en juego la integridad de los conjuntos del Holoceno medio, y por lo tanto, se presentan como muestras comparables para afrontar el estudio que aquí se pretende.

El aprovechamiento integral del guanaco para estos momentos de ocupación, se ve reflejado en la gran cantidad y variedad de marcas de origen antrópico que fueron registradas en estos conjuntos, incluyendo huellas de corte, marcas de raspado, puntos de impacto, alteración térmica, e incluso la presencia de instrumentos óseos en distintos niveles de manufactura (Marchionni 2013, 2015; Miotti y Marchionni 2011, 2013, 2014). No obstante, las marcas de procesamientos registran diferencias en frecuencia entre los conjuntos, mientras que en Capa 4 de $\mathrm{CN}$ es donde estos registros se presentan en mayor cantidad (>15\% del NISP), en UA 2 de CS ( $c a .7,5 \%$ del NISP) y en Capa 2 de AEP-1 (ca. 5\% del NISP) están menos representados. Los distintos análisis realizados acerca de la frecuencia de partes anatómicas y los índices de carne, más comúnmente utilizados para evaluar la utilidad económica del guanaco (Borrero 1990; Lyman 1992), no mostraron resultados significativos, y por tanto, se vuelven 
insuficientes, en esta instancia, para discutir en profundidad si las decisiones de transporte de los guanacos estuvieron vinculadas a la cantidad de carne o médula que las distintas partes pueden aportar a la dieta humana (Marchionni 2013).

\begin{tabular}{|c|c|c|c|c|c|c|c|c|c|c|c|c|c|}
\hline & & \multicolumn{4}{|c|}{ Capa 2 AEP-1 } & \multicolumn{4}{|c|}{ Capa 4 CN-CM } & \multicolumn{4}{|c|}{ UA 2 CS-CM } \\
\hline \multicolumn{2}{|c|}{ Unidad Anatómica. } & NISP & MNE & MAU & $\% \mathrm{MAU}$ & NISP & MNE & MAU & $\% \mathrm{MAU}$ & NISP & MNE & MAU & $\% \mathrm{MAU}$ \\
\hline \multirow{3}{*}{ Cabeza } & Cráneo & 5 & 4 & 2,00 & 28,57 & 20 & 4 & 2,00 & 50,00 & 6 & 4 & 2,00 & 47,06 \\
\hline & Mandíbula & 4 & 2 & 1,00 & 14,29 & 18 & 5 & 2,50 & 62,50 & 5 & 2 & 1,00 & 23,53 \\
\hline & Hioides & & & & & & & & & 1 & 1 & 1,00 & 23,53 \\
\hline \multirow{9}{*}{$\begin{array}{c}\text { Esqueleto } \\
\text { Axial }\end{array}$} & Vert. Atlas & & & & & 2 & 2 & 2,00 & 50,00 & 3 & 2 & 2,00 & 47,06 \\
\hline & Vert. Axis & & & & & 4 & 3 & 3,00 & 75,00 & & & & \\
\hline & Vert. Cervical & 9 & 3 & 0,60 & 8,57 & 10 & 5 & 1,00 & 25,00 & 3 & 2 & 0,40 & 9,41 \\
\hline & V. Cervical & & & & & & & & & & & & \\
\hline & V. Torácica & 6 & 4 & 0,33 & 4,76 & 2 & 2 & 0,17 & 4,17 & 4 & 3 & 0,25 & 5,88 \\
\hline & \begin{tabular}{|l|} 
V. Lumbares \\
\end{tabular} & 6 & 3 & 0,43 & 6,12 & 5 & 2 & 0,29 & 7,14 & 6 & 4 & 0,67 & 15,69 \\
\hline & Sacro & & & & & 9 & 4 & 4,00 & 100,00 & 2 & 2 & 2,00 & 47,06 \\
\hline & Costilla & 12 & 7 & 0,29 & 4,17 & 14 & 13 & 0,54 & 13,54 & 5 & 3 & 0,13 & 2,94 \\
\hline & Esternebra & & & & & 1 & 1 & 0,17 & 4,17 & & & & \\
\hline \multirow{17}{*}{$\begin{array}{l}\text { Miembro } \\
\text { Anterior }\end{array}$} & Escápula & 1 & 1 & 0,50 & 7,14 & 4 & 4 & 2,00 & 50,00 & 5 & 5 & 2,50 & 58,82 \\
\hline & Húmero compl. & 1 & 1 & 0,50 & 7,14 & & & & & & & & \\
\hline & Húmero px & 1 & 1 & 0,50 & 7,14 & 1 & 1 & 0,50 & 12,50 & 1 & 1 & 0,5 & \\
\hline & Húmero df & 23 & 3 & 1,50 & 21,43 & 11 & 3 & 1,50 & 37,50 & 5 & 2 & 1,00 & \\
\hline & Húmero ds & 5 & 4 & 2,00 & 28,57 & 2 & 2 & 1,00 & 25,00 & 5 & 4 & 2,00 & 47,06 \\
\hline & Radiocúb. px & 2 & 2 & 1,00 & 14,29 & 7 & 3 & 1,50 & 37,50 & 2 & 2 & 1,00 & 23,53 \\
\hline & Radiocúb.df & 18 & 2 & 1,00 & 14,29 & 21 & 5 & 2,50 & 62,50 & 9 & 3 & 1,50 & 35,29 \\
\hline & Radiocúb.ds & 5 & 4 & 2,00 & 28,57 & 5 & 2 & 1,00 & 25,00 & 4 & 3 & 1,50 & 35,29 \\
\hline & \begin{tabular}{|l|} 
Cuneiforme \\
\end{tabular} & 3 & 3 & 1,50 & 21,43 & & & & & & & & \\
\hline & Escafoide & 5 & 4 & 2,00 & 28,57 & & & & & & & & \\
\hline & Lunar & 3 & 2 & 1,00 & 14,29 & 1 & 1 & 0,50 & 12,50 & 1 & 1 & 0,50 & 11,76 \\
\hline & Magnum & 7 & 7 & 3,50 & 50,00 & & & & & 1 & 1 & 0,50 & 11,76 \\
\hline & Pisciforme (acces) & 5 & 4 & 2,00 & 28,57 & & & & & & & & \\
\hline & Trapezoide & 1 & 1 & 0,50 & 7,14 & & & & & & & & \\
\hline & Unciforme & 3 & 3 & 1,50 & 21,43 & 3 & 3 & 1,50 & 37,50 & 4 & 4 & 2,00 & 47,06 \\
\hline & Metacarpo px & 4 & 4 & 2,00 & 28,57 & 6 & 5 & 2,50 & 62,50 & 4 & 4 & 1,50 & 35,29 \\
\hline & Metacarpo df & & & & & 2 & 2 & 1,00 & 25,00 & & & & \\
\hline \multirow{17}{*}{$\begin{array}{l}\text { Miembro } \\
\text { Posterior }\end{array}$} & Hemipelvis & 1 & 1 & 0,50 & 7,14 & & & & & 3 & 2 & 1,00 & 23,53 \\
\hline & Fémur px & & & & & 7 & 4 & 2,00 & 50,00 & 4 & 3 & 1,50 & 35,29 \\
\hline & Fémur df & 9 & 2 & 1,00 & 14,29 & 16 & 5 & 2,50 & 62,50 & 4 & 3 & 1,50 & 35,29 \\
\hline & Fémur ds & & & & & 1 & 1 & 0,50 & 12,50 & 1 & 1 & 0,50 & 11,76 \\
\hline & Rótula & & & & & & & & & 1 & 1 & 0,50 & 11,76 \\
\hline & Tibia px & 2 & 1 & 0,50 & 7,14 & 12 & 7 & 3,50 & 87,50 & 8 & 4 & 2,00 & 47,06 \\
\hline & Tibia df & 19 & 4 & 2,00 & 28,57 & 28 & 2 & 1,00 & 25,00 & 20 & 4 & 2,00 & 47,06 \\
\hline & Tibia ds & 2 & 2 & 1,00 & 14,29 & 3 & 2 & 1,00 & 25,00 & 3 & 3 & 1,50 & 35,29 \\
\hline & Astrágalo & 3 & 3 & 1,50 & 21,43 & 1 & 1 & 0,50 & 12,50 & 4 & 4 & 2,00 & 47,06 \\
\hline & Calcaneo & 6 & 3 & 1,50 & 21,43 & 4 & 3 & 1,50 & 37,50 & 1 & 1 & 0,50 & 11,76 \\
\hline & Cuboide & 2 & 2 & 1,00 & 14,29 & 3 & 3 & 1,50 & 37,50 & 2 & 2 & 1,00 & 23,53 \\
\hline & Endocuneiforme & 10 & 10 & 5,00 & 71,43 & 3 & 3 & 1,50 & 37,50 & 2 & 2 & 1,00 & 23,53 \\
\hline & Navicular & 10 & 9 & 4,50 & 64,29 & 3 & 3 & 1,50 & 37,50 & 1 & 1 & 0,50 & 11,76 \\
\hline & Fíbular & 14 & 14 & 7,00 & 100,00 & 1 & 1 & 0,50 & 12,50 & 3 & 3 & 1,50 & 35,29 \\
\hline & Sesamoideos & 19 & 19 & 1,19 & 16,96 & & & & & & & & \\
\hline & Metatarso px & 8 & 6 & 3,00 & 42,86 & 9 & 8 & 4,00 & 100,00 & 4 & 3 & 1,50 & 35,29 \\
\hline & Metatarso df & & & & & 2 & 1 & 0,50 & 12,50 & & & & \\
\hline \multirow{5}{*}{$\begin{array}{l}\text { Autopodios } \\
\text { indiferencia } \\
\text { dos }\end{array}$} & Metapodio df & & & & & 32 & 9 & 2,25 & 56,25 & 63 & 17 & 4,25 & 100,00 \\
\hline & Metapodio ds & 85 & 14 & 3,50 & 50,00 & 7 & 5 & 1,25 & 31,25 & 9 & 4 & 1,00 & 23,53 \\
\hline & $1^{\circ}$ Falange & 44 & 22 & 2,75 & 39,29 & 16 & 8 & 1,00 & 25,00 & 4 & 3 & 0,38 & 8,82 \\
\hline & $2^{\circ}$ Falange & 44 & 24 & 3,00 & 42,86 & 8 & 8 & 1,00 & 25,00 & 4 & 3 & 0,38 & 8,82 \\
\hline & $3^{\circ}$ Falange & 26 & 25 & 3,13 & 44,64 & 1 & 1 & 0,13 & 3,13 & 1 & 1 & 0,13 & 2,94 \\
\hline \multirow{7}{*}{ Otros } & Dient nd (mol/premol) & 25 & & & & 23 & & & & 7 & & & \\
\hline & Vert ND & & & & & & & & & 1 & & & \\
\hline & Articular indet & 1 & & & & & & & & & & & \\
\hline & Falange ND & 27 & & & & & & & & 1 & & & \\
\hline & H. Largo & & & & & & & & & & & & \\
\hline & Piedra gástrica & 1 & & & & & & & & & & & \\
\hline & NISP Total & 487 & & & & 328 & & & & 227 & & & \\
\hline
\end{tabular}

Tabla2. Representación anatómica del guanaco en los conjuntos del Holoceno medio 


\section{Enfoque metodológico}

Los análisis que se efectúan en el presente trabajo se enfocan exclusivamente sobre los especímenes correspondientes a guanaco, debido a la importancia, ya manifiesta, que esta especie tuvo para las sociedades cazadoras-recolectoras que habitaron el área durante el Holoceno medio.

En función de los objetivos que nos planteamos, una primera instancia contempla la evaluación completa de los conjuntos, incluyendo todos los elementos anatómicos determinados como guanaco. Estos análisis consisten en correlacionar estadísticamente las frecuencias de elementos -tanto unidades axiales como apendicularesrepresentados en cada conjunto (\%MAU) y los índices de médula (Mengoni Goñalons 1996) y grasa insaturada (Morin 2007). De esta manera es posible evaluar si la representación de partes anatómicas refleja decisiones que puedan haber estado vinculadas al consumo de médula, sea ésta en función de la cantidad o calidad que ofrece cada parte. Una segunda etapa de análisis, relacionada más específicamente al estudio de la fragmentación de los conjuntos, contempla la selección de los especímenes de hueso largo correspondientes al estilopodio (húmero y fémur), zeugopodio (radio-ulna y tibia) y autopodio (metapodios y $1^{\circ}$ y $2^{\circ}$ falange), por ser elementos que además de contener médula ofrecen tejido óseo compacto útil para la manufactura de artefactos. De esta manera el total de materiales analizados corresponde a 622 especímenes de hueso largo de guanaco, de los cuales el 43,72\% $(\mathrm{NISP}=272)$ son de AEP-1, mientras que el resto son de CM y provienen de la CN $(31,51 \%=196$ de NISP) y de la CS $(24,75 \%=154$ de NISP).

En una primera instancia evaluamos el estado general de fragmentación de los conjuntos a partir de la estimación de la intensidad y la extensión de la fragmentación en cada uno (Lyman 1994; Wolverton 2002). Para ello, por un lado medimos todos los fragmentos de diáfisis de huesos largos y comparamos la clases de tamaños; y por otro, estimamos el índice de fragmentación de cada conjunto a partir de la relación NISP/MNE. La comparación entre las clases de tamaño representadas en cada conjunto se llevó adelante mediante una prueba estadística de Kolmogorov-Smirnov. Esta prueba nos permitió evaluar si las diferencias observadas entre los tres conjuntos eran o no significativas.

Por otra parte, caracterizamos los distintos tipos de fracturas presentes en los especímenes de hueso largo de guanaco. La determinación de los diferentes patrones de fracturas se llevó a cabo en base a los atributos descriptos por Johnson (1985: 172) y Gifford-González (1989). Como complemento de este análisis y a fin de lograr una mejor interpretación de las causas (culturales o naturales) de las fracturas, se consideró también la incidencia que pudieron haber tenido en ellas la meteorización, el pisoteo, los carnívoros y las raíces. De igual manera, utilizamos la información correspondiente a modificaciones culturales y que puedan estar vinculadas a la fracturación intencional de los huesos, como son las marcas de percusión, los puntos de impacto, las marcas de 
raspado y los marcados perimetrales. Asimismo, y también con el objetivo de analizar si el origen de las fracturas es natural o cultural, estimamos el Índice de Fractura Fresca (IFF) propuesto por Outram (2001), que, además de tener en cuenta el tipo y superficie de fractura, considera el ángulo que se forma entre la superficie de la fractura y la superficie cortical del hueso.

\section{Análisis de la fragmentación en guanaco}

Representación de unidades anatómicas y aprovechamiento de médula

Se correlacionaron los valores de \%MAU de cada uno de los conjuntos (Tabla 2) con el índice de médula (Mengoni Goñalons 1996) y el índice de grasa insaturada (Morin 2007). Los resultados muestran correlaciones significativas solamente entre el índice de médula y las frecuencias de unidades anatómicas del conjunto de Capa 2 de AEP-1 y entre el índice de grasa insaturada y los valores de \%MAU de los conjuntos de Capa $4(\mathrm{CN})$ y de UA2 (CS) de CM (Tabla 3). La primera de éstas (\%MAU de Capa 2 AEP-1 y cantidad de médula) es una correlación alta y negativa, la cual nos estaría indicando una fuerte representación de aquellos elementos apendiculares con menor cantidad de médula. Por su parte, la correlación moderada y positiva entre los conjuntos de $\mathrm{CM}$ y el índice de grasa insaturada, nos estaría sugiriendo la probabilidad de que este conjunto sea resultado de decisiones de transporte y aprovechamiento de los guanacos en relación a la calidad de la grasa medular (mayor cantidad de ácido oleico y por lo tanto una médula más palatable).

\begin{tabular}{|l|c|c|c|}
\hline & Capa 2 AEP-1 & Capa 4 CN CM & UA 2 CS CM \\
\hline $\begin{array}{l}\text { Índice de médula } \\
\text { (Mengoni } \\
\text { Goñalons 1996) }\end{array}$ & $\begin{array}{c}-0,805(\mathrm{p}<0,05) \\
\text { Negativa y } \\
\text { significativa }\end{array}$ & $\begin{array}{c}0,045(\mathrm{p}>0.05) \text { No } \\
\text { significativa }\end{array}$ & $\begin{array}{c}0,330(\mathrm{p}>0,05) \text { No } \\
\text { significativa }\end{array}$ \\
\hline $\begin{array}{l}\text { Índice de grasa } \\
\text { insaturada } \\
\text { (Morin 2007) }\end{array}$ & $\begin{array}{c}-0,503(\mathrm{p}>0,05) \text { No } \\
\text { significativa }\end{array}$ & $\begin{array}{c}0,571(\mathrm{p}<0,05) \\
\text { Positiva y } \\
\text { significativa }\end{array}$ & $\begin{array}{c}\text { Significativa } \\
\end{array}$ \\
\hline
\end{tabular}

Tabla 3. Resultados de las correlaciones entre el \%MAU y los distintos índices.

Caracterización general de la fragmentación de los conjuntos

La estimación de la extensión de la fragmentación muestra que ésta ha afectado a casi la totalidad de los huesos largos que conforman los tres conjuntos, las únicas excepciones corresponden a dos elementos enteros (un húmero de neonato y una $1^{\circ}$ falange) registrados en AEP-1 y otros dos (ambos $2^{\circ}$ falanges), registrados en UA2 de $\mathrm{CM}$. De este análisis se desprende que de no mediar procesos tafonómicos que hayan contribuido a la fragmentación de estos elementos, si ésta es resultado de decisiones culturales, no estaríamos notando ninguna tendencia a que la fragmentación halla 
estado dirigida a aquellos elementos que ofrecen mayor cantidad de médula. Asimismo, si consideramos la relación NISP/ MNE encontramos valores similares para los conjuntos de Capa 2 de AEP-1 (NISP: MNE=3,23) y Capa 4 de CN de CM (NISP: $\mathrm{MNE}=3,21)$. Ambos conjuntos presentan los índices más elevados y dan cuenta de una mayor fragmentación que en el conjunto de UA2 de CS de CM (NISP: MNE=1,94) cuyo índice se diferencia indicando una menor fragmentación de los especímenes.

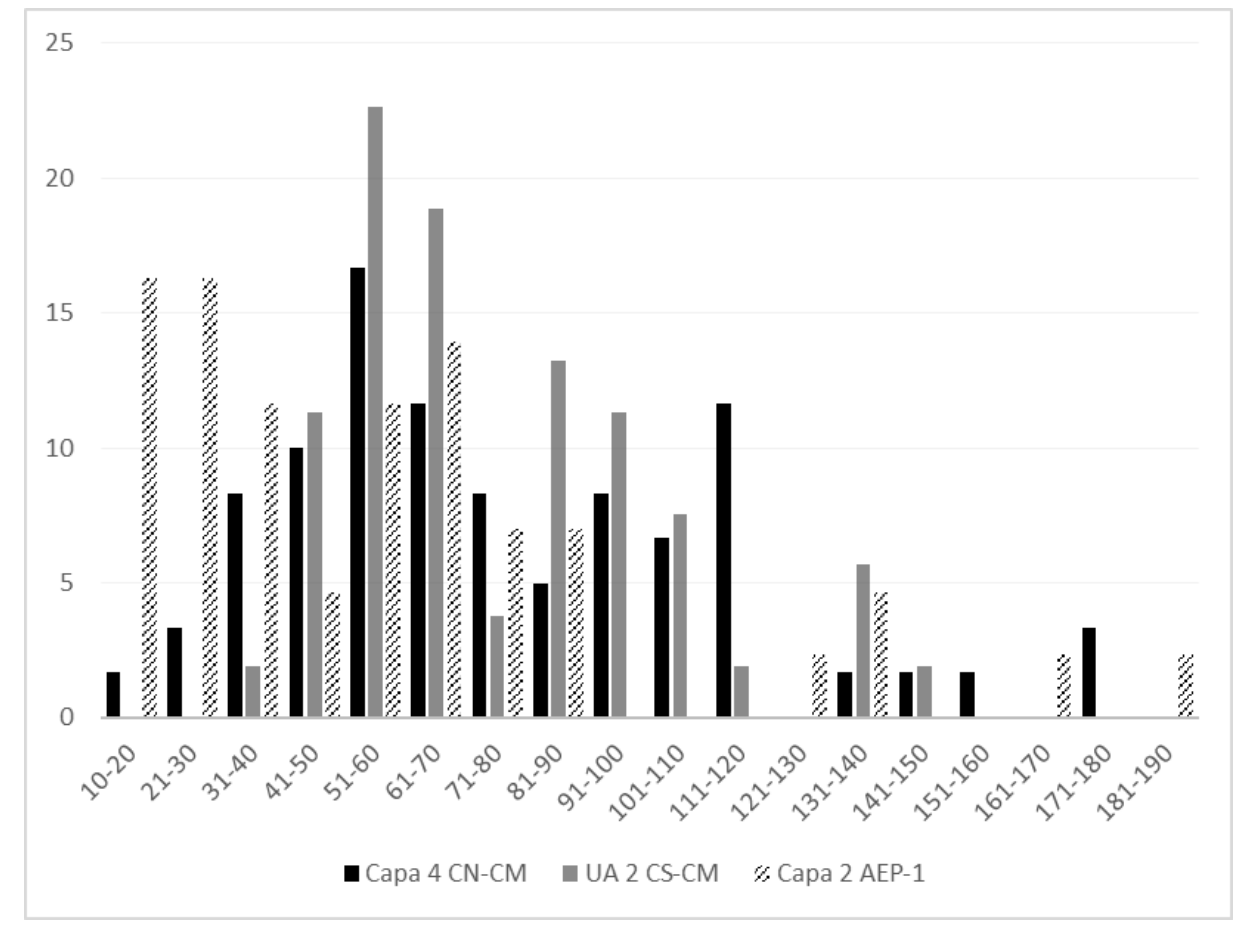

Figura 2. Representación de los fragmentos de diáfisis de hueso largo por clase de tamaño (milímetros). Las frecuencias corresponden al \% NISP de hueso largo.

El análisis comparativo entre clases de tamaño de los especímenes de huesos largos de los tres conjuntos estudiados muestra que los conjuntos de CM tienen una mayor representación de las clases de tamaño mediano, coincidiendo su pico máximo en la categoría que reúne especímenes de entre 51 y $60 \mathrm{~mm}$, mientras que, en AEP-1 hay una fuerte expresión de aquellos especímenes muy pequeños, cuyos tamaños son menores o iguales a $30 \mathrm{~mm}$ (Figura 2). Estas diferencias, al igual que el índice de fragmentación, estarían indicando una mayor intensidad de la fragmentación de este último conjunto respecto de los de $\mathrm{CM}$, lo cual también podría relacionarse con el menor grado de identificabilidad que presenta el conjunto de AEP-1 respecto de los provenientes de CM. No obstante, en AEP-1, los especímenes de entre 51 y $70 \mathrm{~mm}$ también adquieren frecuencias elevadas mostrando así, dos picos principales: fragmentos muy pequeños y fragmentos medianos. El análisis estadístico a partir de la prueba de bondad de ajuste de Kolmogorov-Smirnov para el nivel de significatividad del 5\% muestra la existencia de diferencias significativas en el tamaño que presentan los fragmentos de diáfisis de huesos largo entre ambos conjuntos de $\mathrm{CM}$ y el conjunto de AEP-1, no observándose diferencias estadísticamente significativas entre los conjuntos de CM (tabla 4). 


\begin{tabular}{|l|l|}
\hline Capa 2 AEP-1 contra Capa 4 CN CM & $\mathrm{P}=0,00073(<0,05)$ \\
\hline Capa 2 de AEP-1 contra UA2 CS CM & $\mathrm{P}=0,00413(<0,05)$ \\
\hline Capa 4 CN CM contra UA2 CS CM & $\mathrm{P}=0,1364(>0,05)$ \\
\hline
\end{tabular}

Tabla 4. Resultados de Kolmogorov- Smirnov

Patrones de fractura

Fueron identificadas y descriptas un total de 727 fracturas ya que algunos especímenes presentan más de una, de ellas 261 corresponden al conjunto de AEP-1, 309 a capa 4 de CN-CM y 157 a CS-CM. Los distintos tipos de fracturas identificados en los especímenes apendiculares de los guanacos (Figura 3), permiten observar en los tres conjuntos una mayor representación de aquellas que corresponden a patrones longitudinales y helicoidales. Estos patrones, sumados a los oblicuos y a los transversales con probable surco, serían los que mayor probabilidad tienen de haber sido realizados de manera intencional por los humanos. De esta manera, notamos que en CM más del $80 \%$ de los patrones de fracturas determinados podrían responder a la fracturación intencional de los huesos largos, mientras que en AEP-1 algo más del 75\% del conjunto exhibe estas características (Figura 3). Esta intencionalidad en la fracturación podrían no sólo estar destinada a la obtención de un producto alimenticio, sino también, y tal como se propuso en trabajos previos, para utilizar el hueso como forma base de instrumentos (Miotti y Marchionni 2013, 2014). Distinto a esto es el caso de los patrones transversales que no presentan evidencia de haber sido logrados cuando el hueso se encontraba en estado fresco. En base a los estudios tafonómicos previamente realizados, estos casos son los que más probablemente hayan resultado de procesos de meteorización, ciclos de humedad y sequedad, alteración térmica y posiblemente, en menor medida, de la acción post-depositacional de raíces (Marchionni 2013; Miotti y Marchionni 2011).

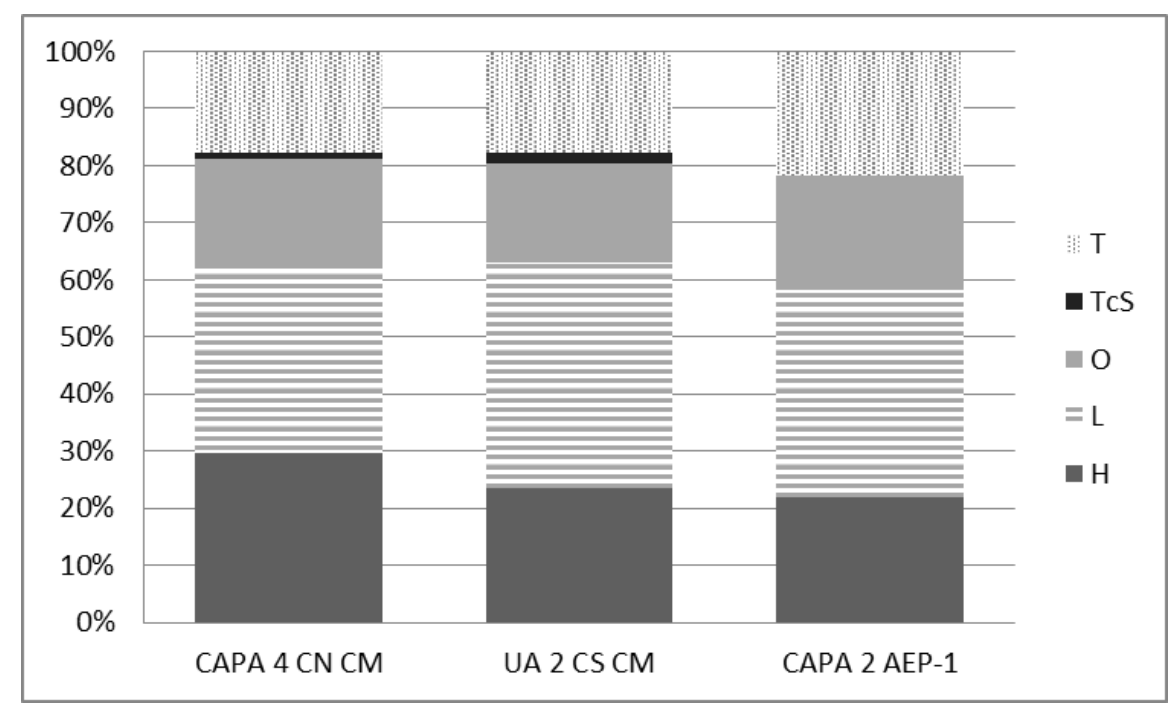

Figura 3: frecuencia porcentual de tipos de fracturas representados por conjunto. T: transversal; TcS: transversal con probable surco; O: oblicua; L: longitudinal; H: Helicoidal. 
Índice de Fractura Fresca

Éste índice fue estimado, tal como se mencionó en el apartado metodológico, solamente en los especímenes correspondientes a diáfisis de hueso largo. La figura 4a muestra la representación de los distintos IFF (valores entre 0 y 6) obtenidos para cada conjunto. Notamos que los valores de IFF 5 y 6 son los menos representados en todos los casos, mientras que los valores más bajos (entre 0 y 4 ) son los más abundantes, aunque las frecuencias de cada uno de ellos varían según el conjunto.
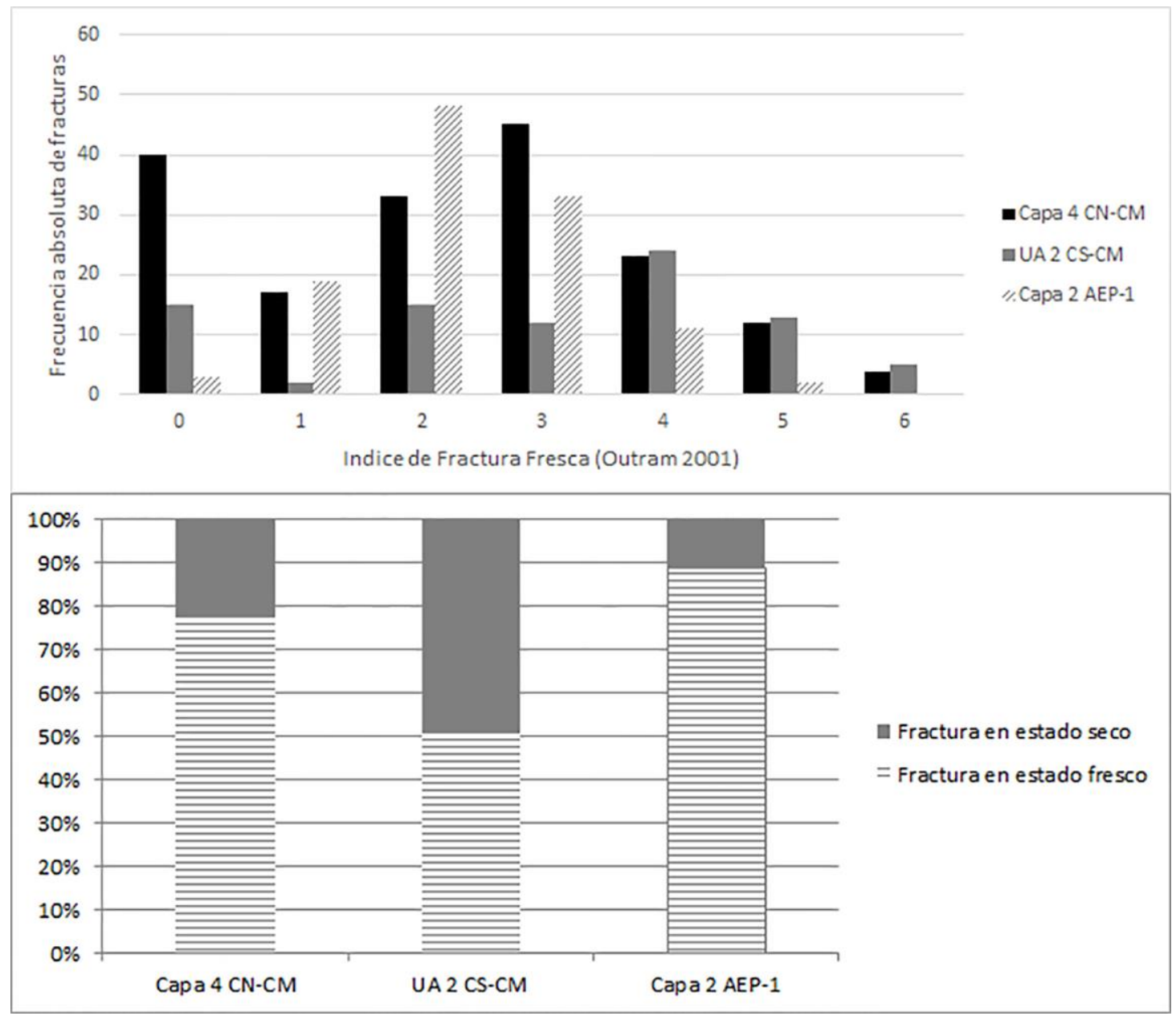

Figura 4. a) Representación de los distintos valores de Índice de Fractura Fresca (Outram 2001) por conjunto; b) Frecuencia porcentual de fracturas producidas en distintos estados del hueso por conjunto.

$\mathrm{Al}$ agrupar los distintos IFF de los especímenes de cada conjunto consideramos los siguientes criterios: valores entre 0 y 3 estarían indicando fracturas que resultan del hueso en estado fresco y valores entre 4 y 6 fracturas efectuadas con el hueso en estado seco (Outram 2001). Notamos que las fracturas en estado fresco representan el mayor porcentaje (más del 75\%) en los conjuntos de Capa 4 de CN-CM y Capa 2 de AEP-1, observándose en este último la mayor de estas frecuencias (ca. 88\%) (Figura 4b). Por su lado, la UA 2 de CM es donde se registra la frecuencia más baja de fracturas frescas ( $c a$. $50 \%$ ). Respecto del IFF por conjunto (valor promedio) notamos la misma tendencia, el 
valor más bajo se observa para la Capa 4 de $\mathrm{CN}$ de $\mathrm{CM}(\mathrm{IFF}=2,26)$ y un valor similar para el conjunto de Capa 2 de AEP-1 (IFF= 2,31). Por el contrario, el valor obtenido para el conjunto de UA 2 de CS-CM (IFF= 3,37) se encuentra levemente por encima del límite que indica una situación de fractura fresca. Tal como fue sostenido por De Nigris (2004), Outram (2001) y otros autores, huesos sometidos a cocción pueden adquirir fracturas con características intermedias como las observadas en UA 2 de CS de Cueva Maripe (García Añino 2018).

Indicadores de fracturación intencional y tecnología ósea

Entre las modificaciones humanas identificadas en estos conjuntos, en la figura 5 se presentan las frecuencias de aquellas vinculadas con la fracturación intencional de los huesos largos -punto de impacto, marcas de percusión y raspado-. Los resultados indican que los conjuntos de $\mathrm{CM}$ son los que reúnen la mayor cantidad de marcas que sugieren este tipo de tarea, siendo más abundantes los indicadores registrados en $\mathrm{CN}$ respecto de CS. Asimismo, y como fue mencionado anteriormente, cada uno de los conjuntos de CM presenta tres epífisis de huesos largos con porción de diáfisis fracturada transversalmente. Si bien no es clara la confección de surco perimetral previo a la fractura en estos elementos y aún su estudio de detalle está en desarrollo, las características que presentan parecen compatibles con las de los llamados "machacadores" (Hajduk y Lezcano 2005) y por lo tanto, sería esperable que esas fracturas hayan sido generadas intencionalmente. Probablemente, lograr ese patrón transversal haya involucrando algún tipo de debilitamiento transversal del tejido cortical con el fin de lograr una fractura controlada y obtener un instrumento óseo.

Finalmente, encontramos evidencias concretas de artefactos óseos en los tres conjuntos estudiados (Figura 6). Tanto en el conjunto de Capa $4 \mathrm{CN}-\mathrm{CM}$ como en Capa 2 de AEP-1 se registran instrumentos óseos confeccionados en huesos largos de guanaco, entre los que se destaca el uso de metapodios, radio-ulna y tibias. En cuanto al conjunto de Capa 2 de CS-CM, también se ha registrado la utilización del hueso como materia prima para la confección de instrumentos o adornos, pero en este caso no hemos podido determinar a nivel más específico que el de mamífero grande los elementos de procedencia, aunque sea altamente probable que correspondan a guanaco. Entre los artefactos se destaca la presencia de percutores blandos (Jackson 1989-90; Marani y Cardillo 2010), fragmentos óseos decorados con incisiones cortas y paralelas, entre otros que hemos denominado, siguiendo a Scheinsohn (1997) como bipunta y punta roma (Miotti y Marchionni 2013). Asimismo, y solo con el interés de reafirmar los usos tecnológicos del hueso, en todos estos conjuntos hemos reconocido manufacturas que también han involucrado a otros taxones como zorros y aves (Marchionni 2013; Miotti y Marchionni 2013). 


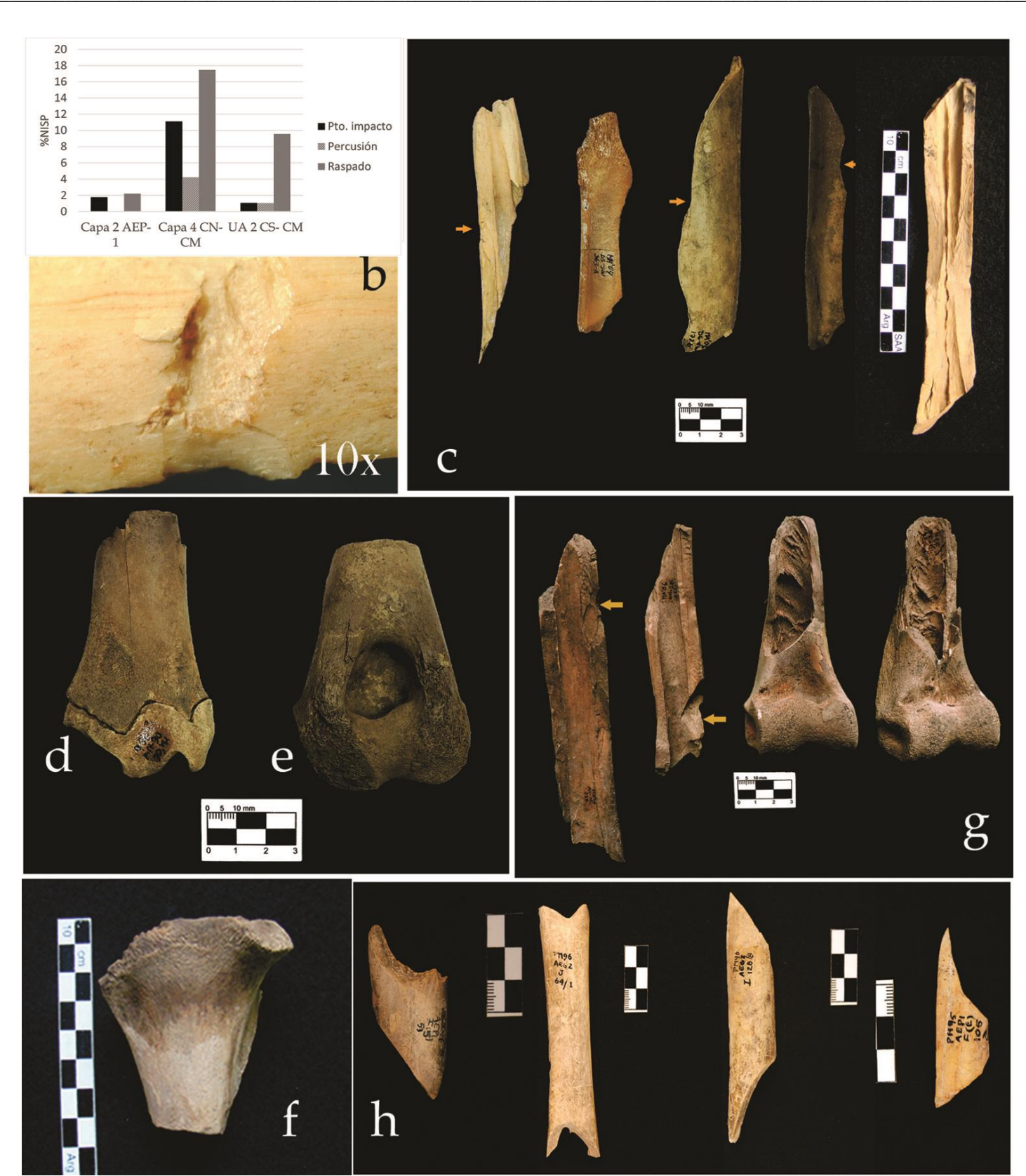

Figura 5. a) Representación de las modificaciones antrópicas por conjunto; b) punto de percusión asociado a marcas de raspado en diáfisis de metapodio de Capa $4 \mathrm{CN}-\mathrm{CM}$; c) fragmentos de diáfisis de hueso largo de guanaco fracturados intencionalmente en Capa 4 $\mathrm{CN}-\mathrm{CM}$; d) Tibia distal de guanaco fracturado transversalmente de manera intencional en

Capa $4 \mathrm{CN}-\mathrm{CM}$; e) húmero distal de guanaco fracturado transversalmente de manera intencional en Capa $4 \mathrm{CN}-\mathrm{CM}$; f) Fémur proximal de guanaco fracturado transversalmente de manera intencional en Capa 4 CN-CM; g) fragmentos de diáfisis de hueso largo de guanaco fracturados intencionalmente en UA 2 CS-CM; h) fragmentos de diáfisis de hueso largo de guanaco fracturados intencionalmente en Capa 2 de AEP-1. 

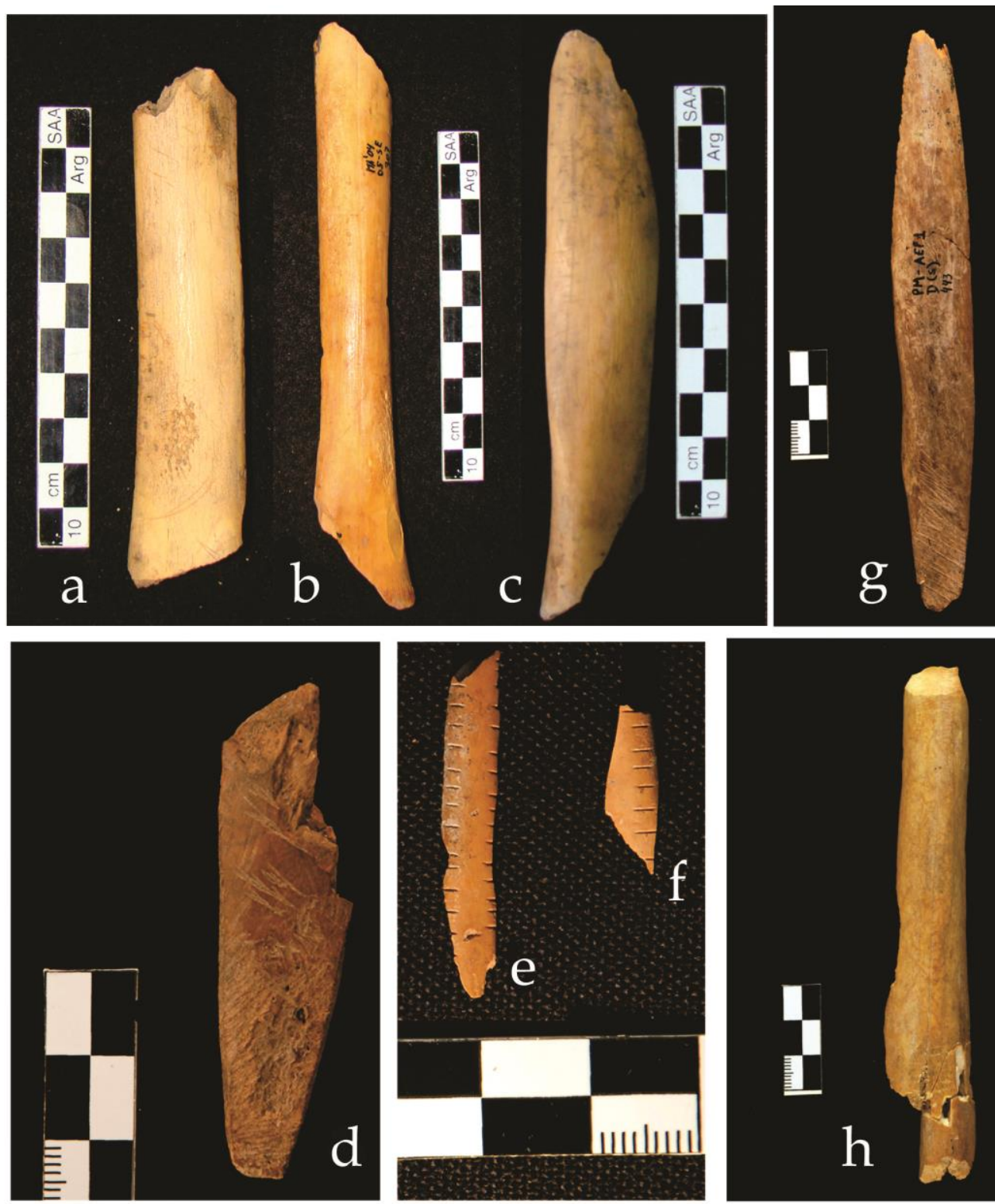

Figura 6: a,b y c) Capa 4 CN-CM artefactos óseos formatizados por uso: a) diáfisis de tibia; b) diáfisis de metapodio; c) diáfisis de radio-ulna; d, e y f) UA 2 CS-CM: d) artefacto óseo formatizado; e y f) fragmentos decorados con líneas incisas paralelas; g y h) Capa 2 AEP-1 artefactos óseos formatizados: g) sobre radio-ulna izquierda de guanaco; h) sobre diáfisis anterior de metapodio.

\section{Discusión y conclusiones}

El estudio comparativo de los conjuntos zooarqueológicos del Macizo del Deseado correspondientes al Holoceno medio nos permite inferir una baja variabilidad entre las estrategias vinculadas al procesamiento secundario de los guanacos. Un primer aspecto a destacar se vincula con la representación de partes anatómicas en uno y otro sitio. Si bien ambos conjuntos concuerdan con las tendencias generales observadas en los conjuntos zooarqueológicos de la región patagónica, caracterizada por la dominancia de elementos apendiculares de los animales, las frecuencias de partes anatómicas representadas en ambos sitios sugiere estrategias de transporte diferentes en cada caso. 
Las correlaciones estadísticas entre el \%MAU y los índices de médula (Mengoni Goñalons 1996) y grasa insaturada (Morin 2007) indican para CM que el transporte e ingreso a la cueva de los guanacos fue en forma trozada. En este sentido las unidades ingresadas parecen responder a la selección de elementos con mejor calidad de la médula ósea (Miotti y Marchionni 2014; Morín 2007) y coincidente mayormente con los cuartos de los animales; en AEP-1 cobra más relevancia el índice de médula (Mengoni Goñalons 1996), pero al correlacionarse negativamente con el \%MAU, nos indica que están más representadas aquellas partes que tienen menos cantidad de este recurso. Si bien la utilidad de estos índices para interpretar la representación de partes anatómicas en contextos de Patagonia viene siendo discutida, éstos constituyen un primer acercamiento para explorar los perfiles anatómicos de los conjuntos, teniendo en cuenta la gran variedad de factores que pueden influir en la toma de decisiones respecto de la selección y transporte de unidades anatómicas a un sitio, así como los procesos post-depositacionales que pueden modificar dicha elección (De Nigris 2008). De esta manera, a pesar que los datos aportados por los índices sirven para analizar la toma de decisiones humanas en relación con algún recurso en particular, es necesario el desarrollo de estudios complementarios, por ejemplo, los que dan cuenta de la fragmentación de los conjuntos, no solo para evaluar si la misma fue con el fin de obtener grasa ósea o medular, sino porque además, esta herramienta se encuentra condicionada por el grado de identificabilidad de los conjuntos arqueofaunísticos. Esa identificabilidad suele disminuir en contextos domésticos, fuertemente marcados por las últimas etapas de procesamiento, el consumo y el descarte de los especímenes óseos (García Añino 2018).

Los análisis efectuados nos muestran que los tres conjuntos están completamente fragmentados, y debido a que los estudios tafonómicos previos indican una buena preservación (Marchionni 2013, 2016; Miotti y Marchionni 2011), entendemos que efectivamente existió un procesamiento de los distintos huesos largos de los guanacos, no observándose selección o preferencia de ciertos elementos sobre otros para ser fragmentados. Encontramos una pequeña diferencia en el índice de fragmentación estimado, que nos muestra que este proceso habría tenido una incidencia levemente mayor sobre el conjunto de AEP-1 y Capa 4 de CN-CM respecto del conjunto de UA 2 CS-CM. Si bien podría proponerse que el mayor índice de fragmentación hallado en Capa 2 de AEP-1 y Capa 4 de CN-CM sugiere una mayor intensidad del procesamiento de los guanacos -sea para la obtención de médula o grasa ósea- que en la UA 2 CS-CM, no podemos descartar que la fragmentación esté afectada por procesos postdepositacionales. Más allá de la buena preservación de estos conjuntos, se reconocieron diferencias en los procesos que intervinieron en la formación de cada uno de los dos contextos estudiados -meteorización, pedogénesis, raíces, humedad- (Marchionni 2013; Miotti y Marchionni 2011), que pudieron aumentar el debilitamiento de los fragmentos óseos, contribuyendo a un incremento de la fragmentación post-depositacional. AEP-1 presenta la mayor relación NISP/MNE, es el conjunto que registra la mayor cantidad de fragmentos óseos pequeños (Figura 2), y de todos los conjuntos analizados es el que presenta una preservación levemente menor (Marchionni 2013, 2016). Sin embargo, los 
valores obtenidos para el IFF (Outram 2001) muestran que el conjunto de AEP-1 es el que presenta el mayor índice de fractura fresca, lo que nos lleva a pensar como más probable que este conjunto sea resultado de un procesamiento más intensivo del guanaco que en CM. En esta misma línea, no descartamos que el procesamiento que registramos en AEP-1 pueda estar dando cuenta de otras estrategias -diferentes a las aquí evaluadas- como pueden ser la fracturación de los huesos en fragmentos pequeños $(<5 \mathrm{~cm})$ para obtener, por medio de hervido, grasa ósea. Trabajos experimentales han demostrado que los fragmentos pequeños permiten optimizar la obtención de este recurso (Church y Lyman 2003) y que la ausencia o baja representación de las epífisis de los huesos largos en conjuntos altamente fragmentados, puede ser indicador de este tipo de actividades (García Añino y Marchionni 2017). Si bien es necesario evaluar con otras herramientas metodológicas la posibilidad que en AEP-1 se hayan procesado elementos para obtener grasa ósea, por el momento creemos que es válido su planteo a modo de hipótesis. Trabajos realizados en Patagonia extra-andina han propuesto el desarrollo de estas estrategias en sitios del Holoceno tardío de la región y han discutido acerca del uso de contenedores cerámicos y no cerámicos que permitan el hervido de los huesos (Bourlot 2009; García Añino 2018).

Si consideramos los distintos patrones de fracturas representados en los conjuntos (Figura 3), ellos nos indican una alta intencionalidad para la obtención de grasa medular (con puntos de impactos en diáfisis y gran cantidad de fracturas longitudinales, oblicuas y helicoidales). Esa intencionalidad también estaría avalada por los índices de fractura fresca obtenidos y la existencia de un patrón de fractura particular en $\mathrm{CM}$ respecto de AEP-1, que podría sugerir prácticas o actividades diferentes entre ambos sitios. Esta diferencia estaría dada principalmente por la presencia en $\mathrm{CM}$ de fracturas transversales logradas intencionalmente y cuyos fines, tal como se mencionó anteriormente, parecen ser tecnológicos, indicando la búsqueda de formas base para la manufactura de instrumentos en hueso o, como fue propuesto por otros autores, ser instrumentos en sí mismos (eg. machacadores sensu Hajduk y Lezcano 2005). La presencia de huesos largos de guanaco seccionados transversalmente también fue registrada en las ocupaciones del Holoceno medio en la cueva 3 de Los Toldos (Miotti 1998; Miotti y Marchionni 2013). Por el momento, estos dos sitios (Los Toldos y CM), son los únicos de la región donde esta tecnología aparece para momentos de ca. 7000-5000 años AP. La cantidad y variedad de instrumentos óseos presentes en los conjuntos del Holoceno medio aquí estudiados (Figura 6) manifiestan la importancia que el hueso tuvo para las sociedades del pasado en cuanto materia prima. La mayor cantidad de instrumentos óseos formales en CM respecto de AEP-1, sumado a la presencia de instrumentos en distintas etapas de formatización, sugieren que en CM es probable que además del uso de instrumentos óseos, se haya llevado a cabo también en el sitio la manufactura de estos artefactos (Marchionni 2013; Miotti y Marchionni 2013, 2014), marcando el desarrollo de actividades diferentes entre los sitios. 
A partir de los análisis realizados creemos que es posible enunciar algunas conclusiones acerca de los conjuntos:

- Tanto las fracturas registradas, como la notable representación de marcas de raspado asociadas a los bordes de fractura en el conjunto de Capa 4 de $\mathrm{CN}-\mathrm{CM}$, estarían mostrando una tendencia a la búsqueda de mayor control de las fracturas, tanto longitudinales como transversales. Estas fracturas podrían tener relación con el consumo de médula rica en ácido oleico (unidades más distales de las patas), pero también con la búsqueda de formas base para la confección de instrumentos óseos.

- En el caso de UA2 de CM y Capa 4 CN-CM, la correlación positiva entre el índice de médula insaturada y las unidades anatómicas presentes en el conjunto sugiere que la selección de partes fracturadas para acceso a la médula posiblemente también estuvo relacionada con la calidad de ese producto. No obstante, los valores obtenidos para el IFF nos conducen a pensar en que esas fracturas tienen altas posibilidades de ser resultado de actividades vinculadas a la cocción de los alimentos (De Nigris 2004; Outram 2001). Esta idea, además, se ve apoyada por un alto porcentaje (ca. $40 \%$ del NISP) de especímenes óseos con signos de exposición al fuego y cuya distribución se presenta asociada a las estructuras de combustión registradas en este nivel del sitio (Marchionni 2013). Asimismo, la presencia tanto de artefactos óseos (Figura 6), como de diáfisis seccionadas transversalmente $(n=3)$, también sustentan la idea que en CM, durante el Holoceno medio tuvo lugar la manufactura de artefactos. Entonces podemos concluir que los artefactos formatizados de AEP-1 podrían corresponder a una cadena operativa diferente y que hayan sido ingresados al sitio como parte del tool kit de los cazadoresrecolectores que ocuparon el abrigo por tiempos más acotados.

- Finalmente, el conjunto de Capa 2 de AEP-1, muestra el mayor porcentaje de fracturas en estado fresco sugiriendo un acceso intencional a la médula ósea. Sin embargo, las correlaciones realizadas nos muestran una mayor representación de aquellos elementos que tienen menor cantidad de médula y ausencia de correlación con el índice de grasa insaturada (no hay selección por calidad de grasa).

- Esta situación, sumada a los resultados obtenidos previamente y que muestran una correlación negativa con el índice de carne (Marchionni 2013), indican que este conjunto podría resultar del descarte de partes de bajo rendimiento económico. Esta condición nos conduce a proponer la posible existencia de otras estrategias de explotación de los guanacos en el sitio, como las vinculadas a la obtención de grasa ósea. Si bien considerar esta posibilidad torna necesario explorar con mayor profundidad respecto del tipo de contenedores que se podrían haber usado ya que no hay evidencia de uso de cerámica para estos momentos, el aprovechamiento de este recurso puede cobrar relevancias debido a que es un producto que permanece estable en los ungulados, incluso en momentos de estrés nutricional en los que, otras grasas se ven reducidas (Brink 1997 en Church y Lyman 2003). De todas formas, éste es el conjunto donde más difícil se nos hace identificar con claridad actividades particulares en relación al procesamiento de los guanacos, y por lo tanto nos surgen varias preguntas que direccionarán los trabajos futuros, como por 
ejemplo ¿Qué sesgos pueden estar generando en las interpretaciones la elevada cantidad de fragmentos de mamífero indeterminado que registramos en los conjuntos?¿Qué tipo de conjuntos zooarqueológicos podrían haber dejado/generado aquellos grupos que por razones particulares no pudieron elegir/seleccionar partes o productos de los guanacos? ¿eso pudo haber limitado o restringido las formas de aprovechar los recursos?

Por último, consideramos que las diferencias encontradas en el procesamiento y uso de los guanacos entre los dos sitios estudiados, en gran medida pueden estar vinculadas a las características particulares que presenta cada uno de los contextos ambientales en los que se emplazan, y las distintas maneras en las que los humanos pudieron relacionarse con las faunas en cada uno de ellos. Mientras AEP-1 ofrece condiciones climáticas de mayor estabilidad durante el ciclo anual y acceso directo a campos de caza, en CM es esperable una mayor estacionalidad climática con un acceso más obstaculizado a los recursos. Este último aspecto estaría relacionado con las características particulares de su emplazamiento en un cañadón estrecho y muy profundo (100 -200 m sobre el fondo del mallín) y en cuyas pampas altas estarían los campos de caza.

Si bien, el aporte de este trabajo a las discusiones sobre las ocupaciones del Holoceno medio de la región es incipiente, y consideramos que esa es una problemática que debe ser abordada desde múltiples líneas de investigación, desde la zooarqueología se contribuye a demostrar la existencia de variabilidad entre sitios en los que la expectativa era la de encontrar representadas más o menos las mismas actividades domésticas. Los resultados obtenidos nos invitan a reflexionar sobre las distintas estrategias que los humanos pudieron desarrollar con la intención de aprovechar a los guanacos como recurso principal, durante un período -Holoceno medio- en el que se registran diversos cambios ambientales y se observan discontinuidades cronológicas en las ocupaciones humanas de la región. En este contexto, los resultados nos permiten sugerir que hacia el Holoceno medio comienzan a aparecer nuevas formas de procesar a los guanacos y que podrían estar involucrando un mayor aprovechamiento de productos de esos animales, como son la grasa ósea. Al considerar esos cambios, pensamos que los mismos pueden estar dando cuenta de diferentes factores que han influido en la vida de las sociedades del pasado. Entre ellos, los cambios ambientales registrados durante el Holoceno medio, caracterizados por el incremento de la aridez, las erupciones cordilleranas del volcán Hudson (H1 y H2) y el ascenso del nivel del mar, que podrían haber llevado a la pérdida de jerarquía de esta región (Mosquera 2018 y bibliografía allí citada), con el consecuente empobrecimiento de los recursos. Bajo estas condiciones, la intesificación (potenciación) en el procesamiento de los guanacos para la obtención de nuevos productos, podría conformar una respuesta de las sociedades humanas a nuevas necesidades. No obstante, para momentos del Holoceno tardío en Patagonia se proponen cambios demográficos (Barrientos y Pérez 2004) y el incremento de los rangos de acción para la búsqueda de recursos, en un contexto de reducción de la movilidad residencial (Goñi 
2010). No descartamos que factores socio-demográficos como estos que se registran para momentos posteriores al $4000 \mathrm{AP}$, también estén relacionados con cambios en el aprovechamiento de los recursos como el que acá encontramos para los guanacos. Pensamos que estas cuestiones en el sector del Macizo pueden estar empezando desde momentos previos al Holoceno tardío y expresándose en esta forma particular de procesamiento para la obtención de grasa por hervido. Sin embargo, hacia el Holoceno tardío en Patagonia el secado de carne de guanaco adquiere relevancia para el consumo diferido del recurso (Aguere 2000; Dellepiane 2019; García Añino 2018). La obtención de grasa ósea también podría guardar relación con este fenómeno y con la necesidad de humectar el charquee con fines de consumo.

Por otra parte, pensamos que esta intensificación del trabajo dentro del procesamiento de las presas debe ser comparada a escala regional mayor debido a las propuestas de corrimientos poblacionales durante el Holoceno medio. Para ello será necesario incorporar nuevos referentes temporales que permitan contrastar la idea de intensificación por estrés ambiental, por aumentos demográficos, por cambios en los rangos de movilidad de las sociedades, o por cambios estrictamente relativos a nuevas formas de procesar los alimentos.

A modo de cierre, los análisis recorridos en este trabajo muestran a la zooarqueología como una vía válida para aproximarse a la variabilidad de actividades que se pueden llevar a cabo dentro de los contextos que estudiamos y que definimos como "domésticos" o de "actividades múltiples".

Agradecimientos: Esta investigación fue financiada a través de los subsidios otorgados por la Agencia Nacional de Promoción Científica y Tecnológica (PICT 0176; PICT 20150102 y PICT 2015-1742), el CONICET (PIP 2015-2017 0153) y la Universidad Nacional de La Plata (PI 665 y 805 FCNyM-UNLP). Queremos agradecer los comentarios realizados por ambos evaluadores anónimos y por Darío Hermo al manuscrito original, todos fueron sugerencias de gran valor y permitieron mejorar este trabajo. Asimismo, queremos agradecer a la Municipalidad de Pico Truncado, a las Familias Ferreiro y Koprowski, y a los amigos de la meseta -Ramón y Chela-, quienes contribuyeron enormemente para que la logística de los trabajos de campo sea posible. Finalmente, un agradecimiento a todos los compañeros que aportaron su valioso tiempo y trabajo tanto en las excavaciones como en el laboratorio.

\section{Bibliografía citada}

Aguerre, A.

1994 Restos óseos guanaco del Alero Charcamata. En Contribución a la Arqueología del Río Pinturas, provincia de Santa Cruz, Gradin, C. y Aguerre, A. (eds.), pp. 229- 243. Búsqueda de Ayllu, Concepción del Uruguay. 
2000 Las Vidas de Pati: en la toldería Tehuelche del Río Pinturas y el después. Universidad de Buenos Aires, Facultad de Filosofía y Letras.

Aguerre, A.; M. I. Pagano y M. I. Scarafoni

1994a Material óseo de fauna guanaco, capa 2 del Alero Cárdenas. En Arqueología y Paleoambiente en la Patagonia Santacruceña Argentina, Aguerre, A. (comp.), pp. 100-109. Búsqueda de Ayllú, Concepción del Uruguay.

1994b Fauna Guanaco: capa 4 y 5 del Alero Cárdenas. En Arqueología y Paleoambiente en la Patagonia Santacruceña Argentina, Aguerre, A. (comp.), pp. 121-128. Búsqueda de Ayllú, Concepción del Uruguay.

Barberena, R.

2008 Arqueología y biogeografía humana en Patagonia meridional. Sociedad Argentina de Antropología, Buenos Aires.

Barrientos, G. y I. Pérez

2004 La expansión y dispersión de poblaciones del norte de Patagonia durante el Holoceno tardío: evidencia arqueológica y modelo explicativo. En Contra viento y marea. Arqueología de Patagonia, Civalero, T, et al. (comp.), pp: 179-195. Instituto Nacional de antropología y Pensamiento Latinoamericano y Sociedad Argentina de Antropología, Buenos Aires.

Belardi, J. B.; T. J. Bourlot y D. Rindel

2010 Representación diferencial de diáfisis y epífisis de huesos largos de guanaco (Lama guanicoe) en contextos arqueológicos de médanos en Patagonia austral: el sitio Río Meseta 1 (lago Tar, provincia de Santa Cruz). En Zooarqueología a principios del siglo XXI: aportes teóricos, metodológicos y casos de estudio, Gutiérrez M. A., De Nigris M., Fernández, P., Giardina, M., Gil A., Izeta, A., Neme G. y Yacobaccio H. (eds.), pp. 119131. Ediciones del Espinillo, Buenos Aires. Borrero, L. A.1990 Fuego-Patagonia bone assemblages and the problem of communal guanaco hunting. En Hunters of the recent past, Davis L. y Reeves B. (eds.), pp. 373-406. Unwin Hyman, Londres.

Borromei, A. M.

2003 Palynology at Piedra Museo Locality, Santa Cruz Province, Argentina. En Where the South Winds Blow: Ancient Evidence of Paleo South Americans, Miotti L., Salemme M. y Flegenheimer N. (eds.), pp. 113-120. Center for the Studies of the First AmericansTexas A\&M University Press, Texas.

Bourlot, T.

2009 Zooarqueología de sitios a cielo abierto en el lago Cardiel, Provincia de Santa Cruz: fragmentación ósea y consumo de grasa animal en grupos cazadores-recolectores del Holoceno tardío. Tesis doctoral inédita de la Facultad de Filosofía y Letras-Universidad Nacional de Buenos Aires, Buenos Aires. 
Bourlot, T., Rindel, D., y Aragone, A.

$2008 \mathrm{La}$ fractura transversa/marcado perimetral en sitios a cielo abierto durante el Holoceno tardío en el noroeste de Santa Cruz. En Libro de resúmenes de las VII Jornadas de arqueología de Patagonia, pp. 20. Ushuaia, Tierra del Fuego.

Carden, N.

2009 Imágenes a través del tiempo: arte rupestre y construcción social del paisaje en la meseta central de Santa Cruz. Sociedad Argentina de Antropología, Buenos Aires.

Cattáneo, R.

2002 Una Aproximación a la Organización de la Tecnología Lítica entre los CazadoresRecolectores del Holoceno Medio/Pleistoceno Final en la Patagonia Austral (Argentina). Tesis doctoral inédita de la Facultad de Ciencias Naturales-Universidad Nacional de La Plata, La Plata.

Church, R. T. y R. L. Lyman

2003 Small fragments make small differences in efficiency when rendering grease from fractured artiodactyl bones by boiling. Journal of Archaeological Science 30: 1077-1084.

Cortegoso, V.; V. Durán y A. Gasco

2014 Arqueología de ambientes de altura de Mendoza y San Juan, Argentina. 1a ed. Mendoza: Ediunc.

Dellepiane, J.M.

2019 Poblamiento y uso del espacio de sectores mesetarios del centro-oeste de Santa Cruz durante el Holoceno tardío. Una aproximación zooarqueológica. Tesis doctoral inédita de la Facultad de Filosofía y Letras- Universidad Nacional de Buenos Aires, CABA.

De Nigris, $\mathrm{M}$.

2004 El consumo en cazadores-recolectores. Un ejemplo zooarqueológico de Patagonia meridional. Sociedad Argentina de Antropología, Buenos Aires.

2008 Modelos de transporte etnoarqueológicos: sobre su aplicabilidad y pertinencia en el interior de Patagonia. En Estudios tafonómicos y zooarqueológicos I, Acosta A., Loponte D. y Mucciolo L. (comps.), pp. 37-55. INAPL-AINA, Buenos Aires.

De Porras, M. E.

2010 Dinámica de la vegetación de la Meseta Central de Santa Cruz durante los últimos 11.000 años a partir del análisis polínico: forzantes bióticos y abióticos. Tesis doctoral inédita de la Facultad de Ciencias Exactas y Naturales- Universidad Nacional de Mar Del Plata, Mar del Plata. 
Durán, V.; A. Gil; G. Neme y A. Gasco

2003 El Verano: Ocupaciones de 8.900 años en la Cueva 1 (Santa Cruz, Argentina). En Arqueología y Paleoambiente en Patagonia Santacruceña Argentina, Aguerre A. (comp.), pp. 93- 120. Nuevo Offset, Buenos Aires.

Frank, A.

2011 Tratamiento térmico y manejo del fuego en sociedades cazadoras-recolectoras de la Meseta Central de Santa Cruz. Tesis doctoral inédita de la Facultad de Ciencias Naturales- Universidad Nacional de La Plata, La Plata.

García Añino, E.

2018 Estrategias de consumo de grandes mamíferos a lo largo del Holoceno entre los cazadores-recolectores de la Meseta Central de Santa Cruz. El caso del guanaco en el sitio Cueva Maripe. Tesis doctoral inédita de la Facultad de Ciencias NaturalesUniversidad Nacional de La Plata, La Plata.

García Añino E. y L. Marchionni

2017 La explotación de grasa ósea como recurso nutritivo. Una aproximación experimental y sus implicancias para el registro arqueofaunístico. BAEX (Boletín de Arqueología Experimental) 12: 135-154.

García Añino, E.; L. Marchionni y L. Miotti

2014 The processing of guanaco in Extra-Andean Patagonia over time. En Libro de Resúmenes ICAZ, pp. 62. San Rafael, Mendoza.

Gifford-González, D.

1989 Ethnographic analogues for interpreting modified bones: Some cases from East Africa. En Bone Modification, Peopling of Americas, Bonnichsen R. y Sorg M. (eds.), pp. 179-246. Center for the study of the first Americans- University of Maine, Orono.

Goñi, R.

2010 Cambio climático y poblamiento humano durante el Holoceno tardío en Patagonia Meridional. Una perspectiva arqueológica. Tesis doctoral inédita. Facultad de Filosofía y Letras, Universidad de Buenos Aires.

Hajduk, A. y M. Lezcano

2005 Un "nuevo-viejo" integrante del elenco de instrumentos óseos de Patagonia: los machacadores óseos. Magallania 33 (1): 63-80.

Hermo, D.

2008 Los cambios en la circulación de las materias primas líticas en ambientes mesetarios de Patagonia. Una aproximación para la construcción de los paisajes arqueológicos de las sociedades cazadoras-recolectoras. Tesis doctoral inédita de la Facultad de Ciencias Naturales- Universidad Nacional de La Plata, La Plata. 
Horovitz, I.

1994 Restos Faunísticos no guanaco del alero Cárdenas, Parte II. En Contribución a la Arqueología del Río Pinturas, provincia de Santa Cruz, Gradin C.0 y Aguerre A. (eds.), pp. 63-72. Búsqueda de Ayllu, Concepción del Uruguay

Jackson, D.

1989-90 Retocadores extremos-laterales en contextos paleo-indios. Anales del Instituto de la Patagonia 19: 121-124.

Johnson, E.

1985 Current developments in bone technology. Advances in Archaeological Method and Theory 8: 157-235.

Lyman, R. L.

1992 Anatomical considerations of utility curves in zooarchaeology. Journal of Archaeological Science 19: 7-22.

1994 VertebrateTaphonomy. Cambridge University Press, Cambrige.

Lynch, V.

2014 Estudio comparativo de la producción y uso de artefactos líticos en el Macizo del Deseado (Santa Cruz, Argentina). Tesis doctoral inédita de la Facultad de Ciencias Naturales- Universidad Nacional de La Plata, La Plata.

Lynch, V., L. Marchionni y E. García Añino

2016 Estudio preliminar del contexto de uso y prácticas de consumo durante el Holoceno Medio en el sitio Cueva Maripe (Prov. Santa Cruz, Argentina). En Libro de resúmenes del XIX CNAA, pp, 124-127. Tucumán. Mancini, M.

1998 Vegetational changes during the Holocene in Extra-Andean Patagonia, Santa Cruz Province, Argentina. Palaeogeography, Palaeoclimatology, Palaeoecology 138: 207-219.

Marani H. y M. Cardillo

2010 Retocadores óseos de Saco Viejo (Río Negro, Argentina). Un enfoque morfogeométrico. En Zooarqueología a principios del siglo XXI. Aportes teóricos, metodológicos y casos de estudio, Gutiérrez, M.; De Nigris, M.; Fernández, P.; Giardina, M.; Gil, A.; Izeta, A.; Neme, G.; y Yacobaccio, H. (eds.), pp. 453-458. Ediciones del Espinillo, Buenos Aires.

Marchionni, L.

2012 Zooarqueología de la Unidad Estratigráfica 2, Holoceno medio del alero AEP-1 de Piedra Museo, Santa Cruz. En Entre Pasados y Presentes III. Estudios contemporáneos en Ciencias Antropológicas, Kuperszmit, N.; Lagos Mármol, T.; Mucciolo, L. y M. Sacchi (comp.), pp. 644-665. Editorial MNEMOSYNE, Buenos Aires. 
2013 Comparación de las distintas historias tafonómicas en conjuntos zooarqueológicos provenientes de la Meseta Central de la provincia de Santa Cruz. Tesis doctoral inédita de la Facultad de Ciencias Naturales- Universidad Nacional de La Plata, La Plata.

2016 Taphonomic study in Argentinian Patagonia: analysis of variability through time and space in the Central Plateau (Santa Cruz Province). Archaeological and Anthropological Scieces 8 (2): 241-255.

Marchionni, L.; L. Miotti y B. Mosquera

2010 El uso de la fauna entre el Pleistoceno final y el Holoceno medio en la Patagonia extra-andina. En Zooarqueología a principios del siglo XXI: Aportes Teórico, metodológicos y casos de estudio, Gutiérrez M, De Nigris M., Fernández P., Giardina M., Gil A., Izeta A., Neme G. y Yacobacio H. (eds.), pp. 259-272. Ediciones del Espinillo, Buenos Aires.

Martínez, G. y M. Gutiérrez

2004 Tendencias en la explotación humana de la fauna durante el Pleistoceno finalHoloceno en la Región Pampeana (Argentina). En Zooarchaeology of South America, Mengoni Goñalons G. L. (ed.), pp. 81-98. BAR International Series, Oxford.

Martínez, G.; Gutiérrez, M. A.; Messineo, P.; Kaufmann, C. y Rafuse D. 2016 Subsistence strategies in Argentina during the late Pleistocene and early Holocene. Quaternary Science Reviews 144: 51-65.

Martínez, G.; Prates, L.; Flensborg, G.; Stoessel, L.; Alcaráz, A.P. y P. Bayala. 2015 Radiocarbon trends in the Pampean region (Argentina). Biases and demographic patterns during the final Late Pleistocene and Holocene. Quaternary International 356: 89-110.

Mengoni Goñalons, G.

1976-80 Los materiales óseos de la Cueva II de Los Toldos (Expedición Menghin) y una aproximación a la metodología de análisis de restos faunísticos. RUNA XIII (1-2): 59-68. 1996 La domesticación de los camélidos sudamericanos y su anatomía económica. En Zooarqueología de camélidos 2, Elkin D. C. y Madero C. M. (eds.), pp. 33-46.

1999 Cazadores de guanacos de la estepa patagónica. Sociedad Argentina de Antropología, Buenos Aires.

Mengoni Goñalons, G. y De Nigris, M. E.

1999 Procesamiento de Huesos Largos de Guanaco en el Sitio Cerro de los Indios 1 (Santa Cruz). En Soplando en el viento, pp. 461-475. Neuquén/Buenos Aires, Universidad de Comahue/Instituto Nacional de Antropología y Pensamiento Latinoamericano.

Miotti, L.

1992 Paleoindian occupation at Piedra Museo Locality, Patagonian Region, Argentina. Current Research in the Pleistocene 9: 30-32.1998 Zooarqueología de la Meseta Central y Costa 
de Santa Cruz: Un enfoque de las estrategias adaptativas aborígenes y los paleoambientes. Museo de Ciencias Naturales de San Rafael, San Rafael.2012 La potenciación de los recursos entre los cazadores-recolectores de Patagonia. Factores, Procesos e implicancias arqueológicas. Archaeofauna 21: 137-160.

Miotti, L. y L. Marchionni

2011 The study of Archaeofauna at Middle Holocene in AEP-1 rockshelter, Santa Cruz, Argentina: Taphonomic implications. Quaternary International 245: 148-158.

Miotti, L. y Marchionni, L.

2013 Beyond Stones: Bone as raw material for Tools in Central plateau of Santa Cruz, Argentinian Patagonia. En From These Bare Bones. Raw materials and the study of worked osseous objects, Choyke, A., y O'Connor, S. (eds.), pp. 116-126. Oxbow Books, London. 2014 Autopodios de guanacos en sitios arqueológicos: equifinalidad entre lo palatable y lo preservado. Revista Chilena de Arqueología, 29 (1): 122-129.

Miotti, L y M. Salemme

1999 Biodiversity, Taxonomic Richness and Generalist-Specialists economical systems in Pampa and Patagonia Regions, Southern South America. Quaternary International 5354: 53-68.

2004 Poblamiento, movilidad y territorios entre las sociedades cazadoras-recolectoras de Patagonia. Complutum 15: 177-206.

Miotti, L.; M. Vázquez y D. Hermo

1999 Piedra Museo: Un Yamnagoo pleistocénico en la colonización de la meseta de Santa Cruz. El estudio de la arqueofauna. em Soplando en el Viento, Goñi R. (ed.), pp. 113-136. Universidad Nacional del Comahue- Instituto Nacional de Antropología y Pensamiento Latinoamericano, Neuquén-Buenos Aires.

Miotti, L.; M. Salemme; D. Hermo; M. Vázquez; N. Carden; M. Giardina y L. Magnin 2005 Aguada del Cuero, un nuevo escalón en la arqueología de la Meseta Central de Santa Cruz. En Actas XIII Congreso Nacional de Arqueología Argentina 4, Berberián E. (ed.), 55-62. Universidad Nacional de Córdoba, Córdoba.

Miotti, L.; M. Salemme y J. Rabassa

2003 Radiocarbon chronology at Piedra Museo Locality. En Where the South Winds Blow: Ancient Evidence of Paleo South Americans, Miotti L., Salemme M. y Flegenheimer N. (eds.), pp. 99-104. Center for the Studies of the First Americans-Texas A \& M University Press, Texas.

Miotti, L.; Marchionni, L.; Mosquera, B.; Hermo, D. y A. Ceraso

2014 Fechados radiocarbónicos y delimitación temporal de los conjuntos arqueológicos de Cueva Maripe, Santa Cruz (Argentina). Revista Relaciones en Antropología 39 (2): 509537. 
Miotti, L.; Tonni E. y L. Marchionni

2018 What happened when the pleistocene megafauna became extinct? Quaternary International 473: 173-189.

Morín, E.

2007 Fat composition, skeletal part selection and Nunamiut decision-making. Journal of Archaeological Science 34: 69-82.

Mosquera, B.

2016 Geoarqueología de los zanjones Blanco y Rojo, Macizo del Deseado, provincia de Santa Cruz. Tesis Doctoral inédita. Facultad de Ciencias Naturales y Museo, Universidad Nacional de La Plata, La Plata.

2018 Análisis de la información radiocarbónica de sitios arqueológicos del Macizo del Deseado, provincia de Santa Cruz, Argentina. Intersecciones en Antropología 19: 25-36.

Muñoz, A. S. y J. B. Belardi

1998 El marcado perimetral en los huesos largos de guanaco de Cañadon Leona (Colecció Junius Bird): implicaciones arqueofaunísticas para Patagonia Meridional. Anales del Instituto de la Patagonia 26: 107-118.

Neme, G. y A. Gil

2008 Biogeografía Humana en los Andes meridionales: tendencias arqueológicas en el sur de Mendoza. Chungara 40: 5-18

2009 Human Occupation and Increasing Mid-Holocene Aridity. Southern Andean Perspectives. Current Anthropology 50(1): 149-163.

Núñez, L.; Cartajena, I.; Grsjean, M.; de Souza, P. y C. Carrasco

2011 Reflexiones sobre el Holoceno Medio en la Puna Occidental: ecorrefugios y la emergencia de complejidad. En Poblaciones humanas y ambientes en el Noroeste argentino durante el Holoceno medio, pp. 89-92.

Outram, A. K.

2001 A new approach to identifying bone marrow and grease exploitation: why the "Indeterminate" fragments should not be ignored. Journal of Archaeological Science 28 (4): 401- 410 .

Paunero, R.; A. Frank; F.Skarbun; G. Rosales; M. Cueto; G. Zapata; M. Paunero; N. Lunazzi y M. Del Giorgio

2007. Investigaciones arqueológicas en sitio Casa del Minero 1, Estancia La María, Meseta Central de Santa Cruz. En Arqueología de Fuego-Patagonia. Levantando piedras, desenterrando huesos... y develando arcanos, Morello F.; Martinic M.; Prieto A. y Bahamonde G. (eds.), pp. 577-588. Ediciones CEQUA, Punta Arena. 
Rabassa, J.

1987 The Holocene of Argentina: a review. Quaternary of South America and Antarctic Peninsula 5: 269-290.

2008 Late Cenozoic glaciations in Patagonia and Tierra del Fuego. En The late Cenozoic of Patagonia and Tierra del Fuego, Rabassa, J. (ed.), pp. 151- 204. New York, Elsevier.

Rabassa, J.; C. Heusser y N. Rutter

1989 Late Glacial and Holocene of Tierra del Fuego. Quaternary of South America and Antarctic Peninsula 7: 327-351.

Rindel, D.

2009 Arqueología de momentos tardíos en el noroeste de la Provincia de Santa Cruz (Argentina): una perspectiva faunística. Tesis doctoral inédita de la Facultad de Filosofía y Letras- Universidad de Buenos Aires, Buenos Aires.

2013 Marcos de referencia y frecuencia de partes esqueletarias de guanaco en sitios de Patagonia Meridional: el caso del Índice de Médula insaturada. En Tendencias teóricometodológicas y casos de estudio en la arqueología de la Patagonia, Zangrando, A. (eds.), pp. 505-513. San Rafael, Museo de Historia Natural de San Rafael.

Salemme, M. y L. Miotti

2008 Archaeological hunter-gatherer landscapes since the latest Pleistocene in FuegoPatagonia. En Late Cenozoic of Patagonia and Tierra Del Fuego, Rabassa J. (ed.), pp. 437483. Elsevier, Nueva York

Santiago, F., Salemme, M.

2016 Instrumentos expeditivos o fracturas intencionales? Aportes a La discusión sobre los "machacadores" óseos de Patagonia. En Libro de resúmenes del III Encuentro Latinoamericano de Zooarqueología, Nogueira de Quiroz, A. (ed.). Universidade Departamento de Arqueologia-DARQ, Aracaju, Brasil.

Scheinsohn, V.

1997 Explotación de materias primas óseas en la Isla Grande de Tierra del Fuego. Tesis doctoral inédita. Facultad de Filosofía y Letras, Universidad Nacional de Buenos Aires.

Wolverton, S.

2002 NISP: MNE and \%Whole in analysis of prehistoric carcass exploitation. North American Archaeologist 23 (2): 85-100.

Yacobaccio, H. D.; Catá, M. P.; Hoguin, R.; Morales, M.; Oxman, B.; Samec, C.; Solá, P.; Tchilingurian, $\mathrm{P}$.

2011 EL holoceno medio en el occidente de la Puna Seca (Argentina). En Poblaciones humanas y ambientes en el Noroeste argentino durante el Holoceno medio, pp: 99-103. 
Zangrando, A.F.; Orquera, L. y E. Piana

2010 Diversificación e intensificación de recursos animales en la secuencia arqueológica del canal Beagle (Tierra del Fuego, Argentina). En Zooarqueología a principios del s. XXI. Aportes teóricos, metodológicos y casos de estudio, Gutiérrez, MA; De Nigris, M.; Fernández, P.M.; Giardina, M.; Gil, A.; Izeta, A.; Neme, G. y H. Yacobaccio (eds.). pp. 359-379, ediciones del Espinillo, Buenos Aires.

Zárate, M. A., G. Neme y A. Gil

2005 Mid Holocene paleoenvironments and human occupation in southern South America. Quaternary International 132 (1): 1-3. 